\title{
Vibrational Spectral Studies, Quantum Mechanical Properties, and Biological Activity Prediction and Inclusion Molecular Self-Assembly Formation of N-N'- Dimethylethylene Urea
}

\author{
Sushma Priya Yeddu ${ }^{1}$, Pooventhiran Thangaiyan ${ }^{2}$, Adamilli Veeraiah ${ }^{3}$, Dharmarpu Vijay ${ }^{3}$, Katta Eswar \\ Srikanth $^{3}$, Ahmad Irfan ${ }^{4,5}$, Renjith Thomas 2 ,*(D) \\ 1 Department of Physics, Adikavi Nannaya University, Rajamahendravaram, Andhra Pradesh, India \\ 2 Department of Chemistry, St Berchmans College (Autonomous), Changanassery, Kerala, India; \\ pooventhiran134@gmail.com (T.P.); \\ 3 Molecular Spectroscopy Laboratory, Department of Physics, DNR College (A), Bhimavaram, A.P., India \\ 4 Research Center for Advanced Materials Science (RCAMS), King Khalid University, P.O. Box 9004, Abha 61413, Saudi \\ Arabia \\ 5 Department of Chemistry, Faculty of Science, King Khalid University, P.O. Box 9004, Abha 61413, Saudi Arabia \\ * Correspondence: renjith@sbcollege.ac.in (R.T.);
}

Scopus Author ID 55481779800

Received: 2.03.2021; Revised: 15.05.2021; Accepted: 18.05.2021; Published: 13.08.2021

\begin{abstract}
A cyclic urea analog, N-N'-dimethylethylene urea, was studied using different spectral methods like FT-IR, FT-Raman, and UV-VIS methods followed by computational simulations. The experimental and simulated spectra are compared, and a detailed assignment of vibrations and potential energy distribution is made. It was followed by various quantum mechanical studies like frontier orbital analysis, energy descriptors, average local ionization energies, and nonlinear optical properties. The NBO gave an insight into the various intramolecular stabilizing electron delocalization by hyperconjugation. Noncovalent interaction analysis provided various types of interactions present in the molecule. We also studied ALIE, local information entropy, electron localized function, reduced density gradient studies, localized orbital locator studies, and other analyses. Molecular docking results indicated that this urea derivative acted as an ATP-hydrolysing inhibitor, and the drug delivery ability of cyclodextrin on NND was tested by forming an inclusion complex with both compounds with dispersion and without dispersion interaction.
\end{abstract}

Keywords: DFT; NND; ALIE; NCI; drug delivery.

(C) 2021 by the authors. This article is an open-access article distributed under the terms and conditions of the Creative Commons Attribution (CC BY) license (https://creativecommons.org/licenses/by/4.0/).

\section{Introduction}

Heterocyclic compounds of nitrogen are of significant importance in biology and chemistry due to their prolific uses in the pharmaceutical industry. Among them, cyclic ureatype analogs are found to show a variety of applications in different fields, especially in the medicinal and agricultural disciplines [1]. Disubstituted urea has ample therapeutic activities, for instance, potent inhibitors of different parasites like worms, plasmodium, HIV, diuretic activity, pain-relieving properties, activity against bacteria, algae, and fungi [2-5]. N, N'disubstituted urea derivatives can effectively control and inhibit soluble epoxide hydrolase, both in vivo and in vitro. They are also used to treat Raynaud disease, respiratory distress, high 
blood pressure, complications arising from diabetics, rheumatoid arthritis, and kidney complications [6].

This manuscript presents the detailed experimental and computational study of structure, spectra, and applications of a simple heterocyclic urea derivative N-N'dimethylethylene urea (NND). Shababan discussed the structure and the IR spectrum of this compound, but it lacks the detailed study of the electronic properties, molecular properties, reactivity descriptors, biological studies, drug delivery properties, and other basic studies [7]. Hence we decided to pursue this molecule in detail for its structure, electronic properties, physicochemical properties, noncovalent interactions, and potential biological activities using experimental and computational methods [8-15]. We have used various spectral methods like IR, UV, and Raman to investigate the compound's structural features. The biological activity was also predicted using the PASS study and found that it is active as an inhibitor of ATP hydrolysis. Being a drug, drug delivery is also important. We tried whether this compound can be used along with cyclodextrin by forming a molecular inclusion compound and simulated the complex with and without dispersion [16-21].

\section{Materials and Methods}

The compound was purchased from Sigma Aldrich and used as such for all the experimental studies. The compound's FT-IR and FT Raman spectra were recorded using a Nicolet FT-IR spectrometer and a Nicolet Magna Raman spectrometer equipped with Nd: YAG laser source and InGaAs detector, respectively. UV-Vis spectrum was recorded using Specord Spectrometer at room temperature with DMSO as the solvent.

The first step in the computational section is optimizing the molecule using Gaussian 09 software [22]. We optimized the molecule using the DFT formalism with B3LYP functional [23-27] and 6-311++G (d,p) basis set [28-32]. The same level is used for generating IR and Raman spectra of the compounds. Frequency calculations ensured that there are no imaginary frequencies in the simulated spectrum such that it corresponds to a global minimum. The scaled IR and Raman frequencies are compared with experimental values and found in close agreement. Detailed potential energy distribution and vibration assignments were performed for the compound. The NBO computations were carried out with NBO 3.1 program [33]. Gauss Sum [34] software was employed to study the calculated spectra. Reaction sites of NND were calculated using Multiwavefunction [35] software for calculating total electrostatic potential, average localized ionization energy, and noncovalent interactions. NND biological activity received from PASS online [36] the site, suitable PDB ID downloaded from RCSB [37] site, the energy received from SwissDock [37] and the score values received from PatchDock $[38,39]$ and docked results collected from bio-discovery studio [40] software.

\section{Results and Discussion}

\subsection{IR and RAMAN spectra.}

The molecule was optimized to a minimum conformation using DFT with B3LYP functional and $6-311+\mathrm{G}(\mathrm{d}, \mathrm{p})$ basis set and is given in Figure 1. The presence of no imaginary frequencies ensured that we got a minimum energy geometry. The generated scaled IR and Raman spectra using the same theoretical level were compared with the experimental obtained FT-IR and FT-Raman spectrum and found in close agreement. From the local symmetry coordinates with appropriate scale factors (supplementary material Table S1), the vibrational 
assignments are made according to the PED matrix (Table 1). The comparative FT-IR and FTRaman spectra are shown in Figure 2 and Figure 3.

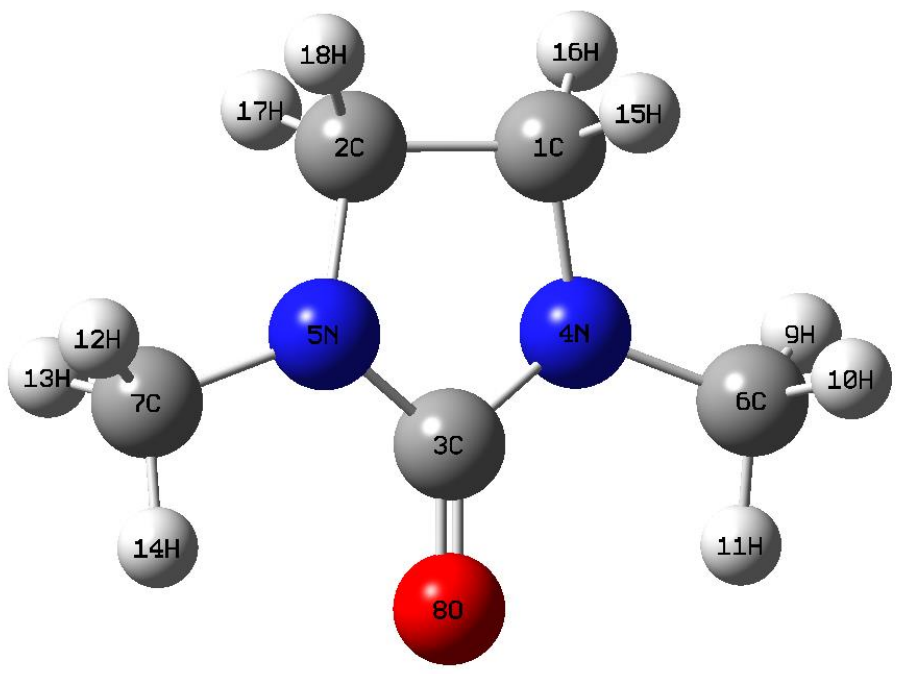

Figure 1. Optimized geometry structure of N-N'-dimethylethyleneurea.

Table 1. Detailed assignments of fundamental vibrations of N-N'-dimethylethylene urea by normal mode analysis based on SQM force field calculations using B3LYP/6-311++G(d,p).

\begin{tabular}{|c|c|c|c|c|c|}
\hline \multirow[b]{2}{*}{$\begin{array}{c}\text { Mode } \\
\text { no. }\end{array}$} & \multicolumn{2}{|c|}{ FT-IR } & \multicolumn{2}{|c|}{ Activity } & \multirow[b]{2}{*}{ Assignments (PED) $)^{\mathrm{a}, \mathrm{b}}$} \\
\hline & $\begin{array}{c}\text { Experimental } \\
\text { frequencies } \\
\left(\mathrm{cm}^{-1}\right) \\
\end{array}$ & $\begin{array}{c}\text { Theoretical } \\
\text { frequencies } \\
\left(\mathrm{cm}^{-1}\right)\end{array}$ & IR & RAMAN & \\
\hline 7 & $3272 \mathrm{v}$ & 3134 & 1.970 & 102.70 & v CH3op (98) \\
\hline 8 & & 3133 & 34.109 & 6.922 & v CH3op (98) \\
\hline 9 & & 3072 & 61.341 & 98.607 & v CH2as (48) \\
\hline 10 & 3059 vs & 3059 & 10.439 & 72.427 & v CH2as (46) \\
\hline 11 & & 3044 & 60.865 & 36.565 & v CH3ip (98) \\
\hline 12 & & 2965 & 7.507 & 129.916 & v CH3ip (98) \\
\hline 13 & 2935 vs & 2935 & 75.638 & 206.876 & v CH2ss (91) \\
\hline 14 & $2857 \mathrm{~s}$ & 2860 & 57.379 & 24.619 & v CH2ss (94) \\
\hline 15 & & 2460 & 0.065 & 287.464 & v CH3ss (99) \\
\hline 16 & 2459 vs & 2459 & 138.460 & 0.211 & v CH3ss (99) \\
\hline 17 & & 1770 & 19.063 & 15.609 & $\beta$ CH3ib ( 79), $\beta$ CH3ob ( 20) \\
\hline 18 & 1687 vs & 1687 & 0.123 & 17.364 & $\beta$ CH3ib (69), $\beta$ CH3ob (15) \\
\hline 19 & $1500 \mathrm{~s}$ & 1528 & 266.570 & 6.696 & v $\mathrm{CN} \quad(43), v \mathrm{CO} \quad$ (20) \\
\hline 20 & & 1513 & 300.510 & 1.846 & v $\mathrm{CN} \quad(57)$ \\
\hline 21 & & 1456 & 35.716 & 5.945 & $\beta \mathrm{CH} 2 \mathrm{sc}(62), \beta \mathrm{CH} 2 \mathrm{tw}(26)$ \\
\hline 22 & $1436 \mathrm{~s}$ & 1435 & 14.549 & 10.245 & $\beta \mathrm{CH} 2 \mathrm{sc}(80)$ \\
\hline 23 & & 1425 & 0.138 & 13.686 & $\beta \mathrm{CH} 2 \mathrm{tw}(57), \beta \mathrm{CH} 2 \mathrm{sc}(31)$ \\
\hline 24 & & 1408 & 10.103 & 5.130 & v CN $\quad(37), \beta \mathrm{CH} 3 \mathrm{sb}(33)$ \\
\hline 25 & & 1400 & 9.416 & 10.492 & $\beta \mathrm{CH} 3 \mathrm{sb}(53), \beta \mathrm{CH} 2 \mathrm{tw}(21)$ \\
\hline 26 & $1397 \mathrm{~s}$ & 1395 & 38.396 & 4.135 & $\beta \mathrm{CH} 3 \mathrm{sb}(38), \beta \mathrm{CH} 2 \mathrm{tw}(34)$, v CN \\
\hline 27 & & 1389 & 57.629 & 3.002 & $\beta$ CH3sb ( 44), v CN $\quad(24), \beta$ Rsym (16) \\
\hline 28 & & 1343 & 37.803 & 4.308 & v CN $\quad(30), \beta \mathrm{CH} 2 \mathrm{tw}(28), \beta \mathrm{CH} 3$ or $(18)$ \\
\hline 29 & & 1312 & 58.702 & 6.080 & $\beta \mathrm{CH} 3$ or $(24), v \mathrm{CN} \quad(24), v \mathrm{CO} \quad(20)$ \\
\hline 30 & $1274 \mathrm{~s}$ & 1266 & 101.93 & 1.520 & $\beta \mathrm{CH} 2$ wa (66), v CN (21) \\
\hline 31 & $1242 \mathrm{w}$ & 1254 & 1.756 & 26.311 & $\beta \mathrm{CH} 2$ wa (39), $\beta$ CH3or ( 26) \\
\hline 32 & $1203 \mathrm{~s}$ & 1194 & 56.618 & 0.842 & $v \mathrm{CN} \quad(43), \beta$ CH3or (33), $\beta$ CH3ob (15) \\
\hline 33 & & 1152 & 0.464 & 7.155 & $\beta$ CH3ir ( 47) \\
\hline 34 & & 1132 & 3.384 & 6.802 & $\beta$ CH3ir (46), $\beta$ CH3ob (24), $\beta$ CH3ib (18) \\
\hline 35 & $1076 \mathrm{vw}$ & 1091 & 4.312 & 12.199 & $\beta$ CH3ob (38), v CN (19), $\beta$ CH3ib (18) \\
\hline 36 & & 1060 & 0.912 & 1.629 & $\beta \mathrm{CH} 2$ ro $(56), \beta \mathrm{CH} 3 \mathrm{ob}(17)$ \\
\hline 37 & $1024 \mathrm{w}$ & 1037 & 6.309 & 8.185 & $\beta \mathrm{CH} 3 \mathrm{ob}(48), \beta \mathrm{CH} 3 \mathrm{ib}(21)$, v CN \\
\hline
\end{tabular}




\begin{tabular}{|c|c|c|c|c|c|}
\hline \multirow[b]{2}{*}{$\begin{array}{c}\text { Mode } \\
\text { no. }\end{array}$} & \multicolumn{2}{|c|}{ FT-IR } & \multicolumn{2}{|c|}{ Activity } & \multirow[b]{2}{*}{ Assignments (PED) ${ }^{\text {a, b }}$} \\
\hline & $\begin{array}{c}\text { Experimental } \\
\text { frequencies } \\
\left(\mathrm{cm}^{-1}\right)\end{array}$ & $\begin{array}{l}\text { Theoretical } \\
\text { frequencies } \\
\quad\left(\mathrm{cm}^{-1}\right)\end{array}$ & IR & RAMAN & \\
\hline 38 & & 994 & 13.891 & 4.036 & $\beta \mathrm{CH} 3 \mathrm{ob}(53), \beta \mathrm{CH} 3 \mathrm{ib}(22)$ \\
\hline 39 & $985 \mathrm{vs}$ & 972 & 2.306 & 3.232 & $\beta \mathrm{CH} 3 \mathrm{ob}(57), \beta \mathrm{CH} 3 \mathrm{ib}(24)$ \\
\hline 40 & $961 \mathrm{vs}$ & 952 & 13.873 & 6.192 & $\beta \mathrm{CH} 3 \mathrm{ob}(44), \beta \mathrm{CH} 3 \mathrm{ib}$ ( 19), v CC \\
\hline 41 & $858 \mathrm{~s}$ & 855 & 6.658 & 0.934 & $\beta \mathrm{CH} 2$ ro (64) \\
\hline 42 & 759 vs & 759 & 20.811 & 0.971 & $\omega \mathrm{CO} \quad(67), \tau$ Rsym (21) \\
\hline 43 & & 730 & 19.431 & 20.405 & v CN $\quad$ (63), v CO (29) \\
\hline 44 & $648 \mathrm{w}$ & 652 & 8.003 & 3.016 & $\beta$ Rasy (41) \\
\hline 45 & $581 \mathrm{~s}$ & 577 & 18.084 & 2.030 & $\beta$ Rsym (51), v CN (28) \\
\hline 46 & & 521 & 5.546 & 0.889 & $\beta \mathrm{NCO} \quad(34), v \mathrm{CN} \quad(25), \beta \mathrm{NC} \quad$ (19) \\
\hline 47 & & 322 & 13.513 & 1.404 & $\beta \mathrm{NC} \quad(63), \beta \mathrm{NCO} \quad(19)$ \\
\hline 48 & & 272 & 0.405 & 0.013 & $\beta \mathrm{NC} \quad(70)$ \\
\hline 49 & & 262 & 2.151 & 0.902 & $\omega \mathrm{CN} \quad(43), \tau$ Rasy (36) \\
\hline 50 & & 220 & 8.769 & 0.495 & $\tau$ Rsym (48), $\omega$ CN (36) \\
\hline 51 & & 187 & 0.008 & 0.369 & $\omega \mathrm{CN} \quad(51), \tau$ Rasy (28) \\
\hline 52 & & 165 & 1.676 & 0.563 & $\tau$ NCH3 $\quad(63), \tau$ Rsym (22) \\
\hline 53 & & 159 & 0.005 & 0.842 & $\tau \mathrm{NCH} 3 \quad(67), \tau$ Rasy $\quad(15)$ \\
\hline 54 & & 113 & 8.543 & 0.130 & $\omega \mathrm{CN} \quad(78)$ \\
\hline
\end{tabular}

a Only PED contributions $\geq 15 \%$ are listed by DFT method. (RMS FREQUENCY ERROR: 0.832E+01)

b Abbreviations: $v$, stretching; $\beta$, in-plane bending; $\omega$, out of plane bending; $\tau$, torsion, ss, symmetrical stretching, as, asymmetrical stretching, sc, scissoring, wa, wagging, twi, twisting, ro, rocking, ipb, in-plane bending, opb, out-of-plane bending; tri, trigonal deformation, sym, symmetrical deformation, asy, asymmetric deformation, butter, butterfly, ar, aromatic, sub, substitution, vs, very strong; s, strong; ms, medium strong; w, weak; vw, very weak.

For the compound, $v \mathrm{CH} 3$ op vibrations are assigned at $3272 \mathrm{~cm}^{-1}$ (IR) and at $3134 \mathrm{~cm}^{-}$ ${ }^{1}$ theoretically $v \mathrm{CH} 3$ symmetric stretching vibrations are allocated at $2459 \mathrm{~cm}^{-1}$ (IR) and theoretically at $2459 \mathrm{~cm}^{-1} . \beta \mathrm{CH} 3$ vibrations are observed at 1687,1436,1397,1076,985,961 $\mathrm{cm}^{-1}$ (IR) and theoretically from $1770-952 \mathrm{~cm}^{-1}$ region.

$v$ CH2 symmetric stretching vibrations are allocated at $2459 \mathrm{~cm}^{-1}$ (IR) and theoretically at $2459 \mathrm{~cm}^{-1}$. $v \mathrm{CH} 2$ as vibrations are allocated at $3059 \mathrm{~cm}^{-1}$ (IR and Raman) and theoretically at $3059 \mathrm{~cm}^{-1}$. $\beta \mathrm{CH} 2 \mathrm{sc}, \mathrm{CH} 2 \mathrm{wa}, \mathrm{CH} 2 \mathrm{tw}, \mathrm{CH} 2 \mathrm{ro}$, vibrations are observed at 1436, 1397, 1274 , $858 \mathrm{~cm}^{-1}$ and 1435, $1395,1266,855 \mathrm{~cm}^{-1}$ using DFT.

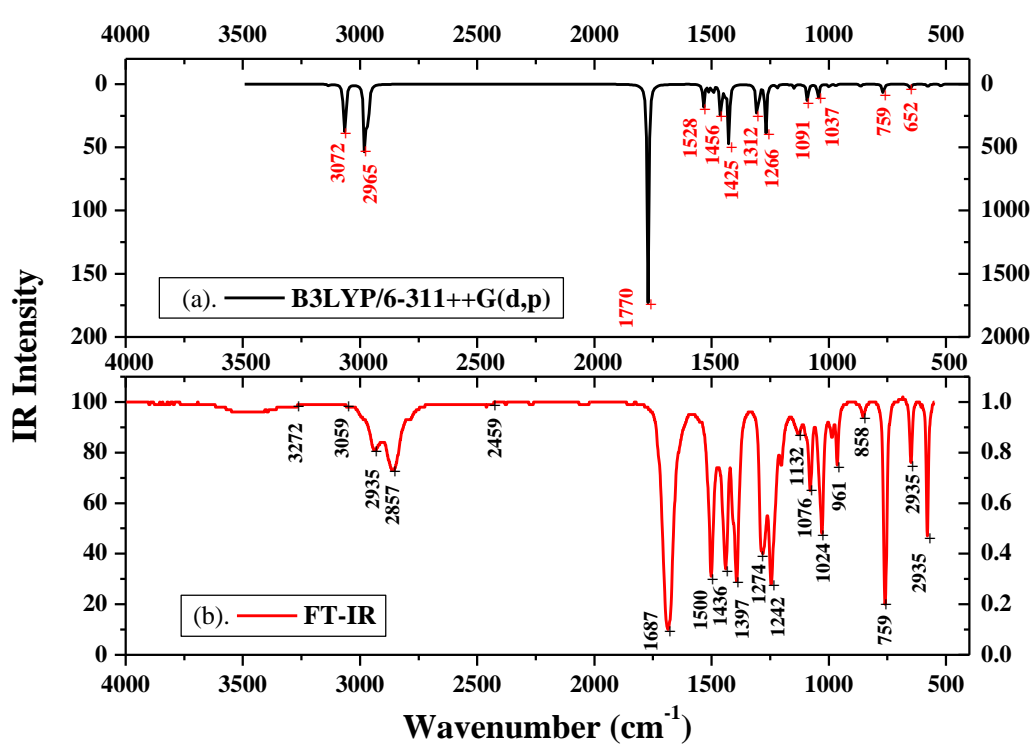

Figure 2. FT-IR experimental and simulated spectrum of N-N'-dimethylethyleneurea. 


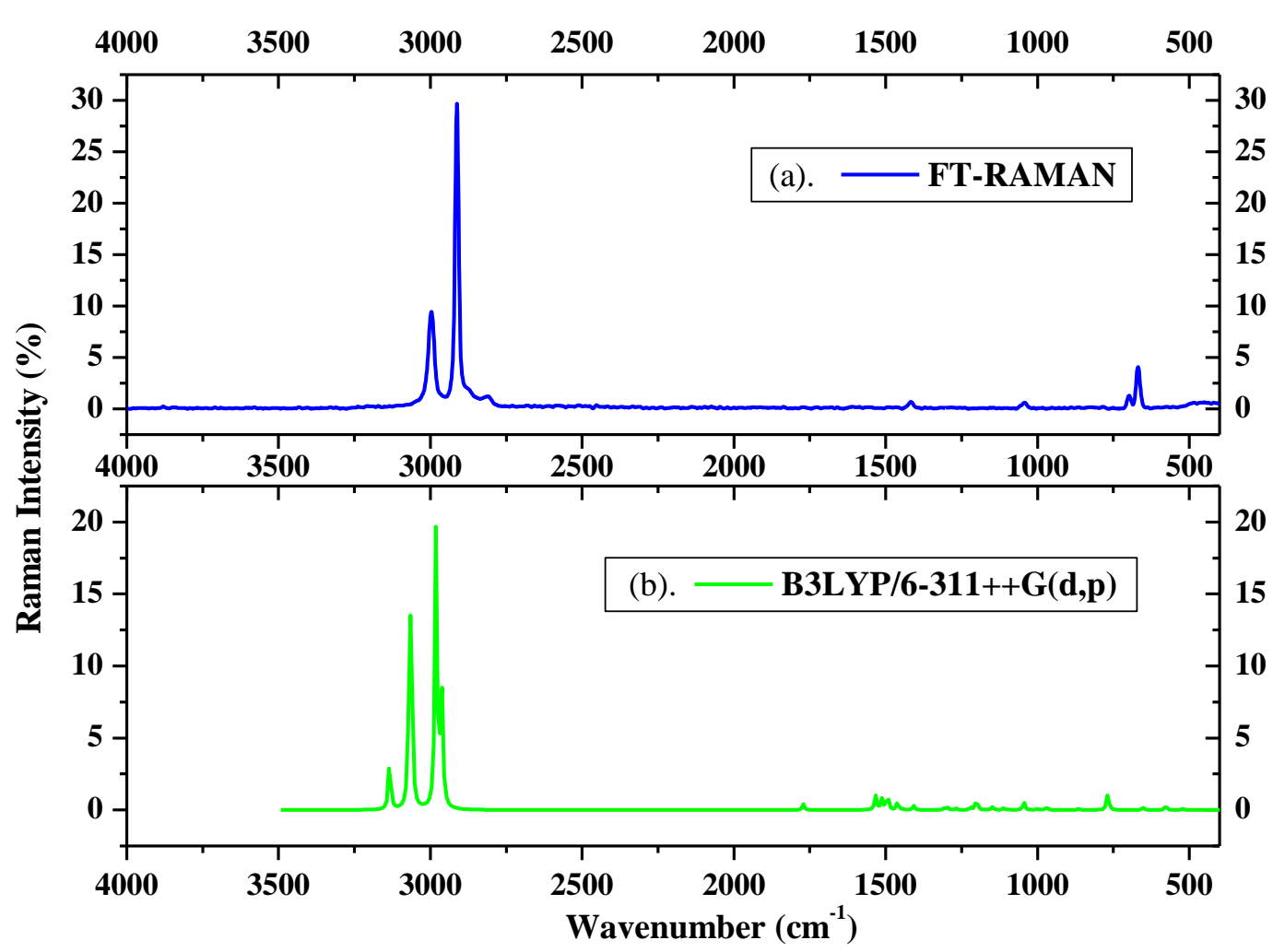

Figure 3. FT-Raman experimental and simulated spectrum of N-N'-dimethylethyleneurea.

The assignment of $\mathrm{CN}$ vibrations is a difficult task since the mixing of vibrations occurs in this region. $v \mathrm{CN}$ vibrations are observed at $1500 \mathrm{~cm}^{-1}$ (IR) and by DFT calculations at 1528 $\mathrm{cm}^{-1}$, and $\beta \mathrm{NC}$ vibrations are observed theoretically at $322 \mathrm{~cm}^{-1} . \omega \mathrm{CO}$ vibrations are measured at $759 \mathrm{~cm}^{-1}$ (IR) and through DFT at $759 \mathrm{~cm}^{-1}$. Ring Symmetric and antisymmetric vibrations are observed at 581, $648 \mathrm{~cm}^{-1}$ (IR) and theoretically at 577, $642 \mathrm{~cm}^{-1}$. The observed and calculated wavenumbers show good coincidence.

\section{2. $U V$-visible spectrum.}

The Experimental UV-visible spectrum of the title compound is shown in figure 4. The maximum absorption peak is observed at $256.50 \mathrm{~nm}$. The peak suggests that the absorption is due to electron transition from $n-\pi^{*}$, which is the only transition for the $\mathrm{C}=\mathrm{O}$ bond. Moreover, the observed shift is due to the presence of auxochrome together with the interaction of solvent DMSO. The UV-Vis excitation wavelength and absorbance of the compound are shown in Table 2.

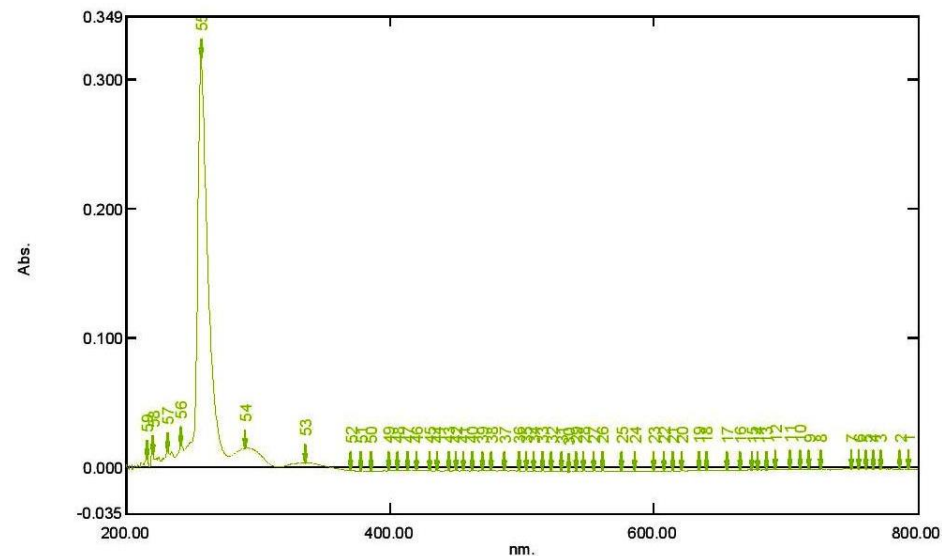

Figure 4. Experimental UV-Vis spectrum of N-N'-dimethylethylene urea. 
Table 2. Experimental UV data of N-N'-dimethylethylene urea.

\begin{tabular}{c|c} 
Wavelength & Absorbance \\
\hline 336 & 0.004 \\
\hline 314.5 & 0.001 \\
\hline 290.5 & 0.015 \\
\hline 278 & 0.009 \\
\hline 256.5 & 0.317 \\
\hline 243.5 & 0.014 \\
\hline 241.5 & 0.018 \\
\hline 236.5 & 0.008 \\
\hline 231.5 & 0.013 \\
\hline 226.5 & 0.005 \\
\hline 219.5 & 0.011 \\
\hline 217.5 & 0 \\
\hline 215.5 & 0.007
\end{tabular}

\subsection{Frontier molecular orbitals of NND.}

The HOMO-LUMO graph is shown in Figure 6, and HOMO is delocalized over the molecule, whereas LUMO is localized over the methylene group of the phenyl ring. The calculated HOMO and LUMO energies, ionization potential $\left(\mathrm{I}=-\mathrm{E}_{\mathrm{HOMO}}\right)$, electron affinity $(\mathrm{A}=-$ $\mathrm{E}_{\mathrm{LUMO}}$ ), and HOMO-LUMO energy gap were computed as 6.4651, 0.4059, and $-6.0591 \mathrm{eV}$, which shows the reactivity of the compound with less energy gap. Moreover, the quantum mechanical parameters such as chemical hardness $\eta=(\mathrm{I}-\mathrm{A}) / 2=6.2621$, chemical potential $\mu=-$ $(\mathrm{I}+\mathrm{A}) / 2=3.4355$ and Electrofilicity index $\omega=\frac{\rho^{2}}{2 \eta}=0.9424$ and other essential parameters were calculated and tabulated in Table 3.

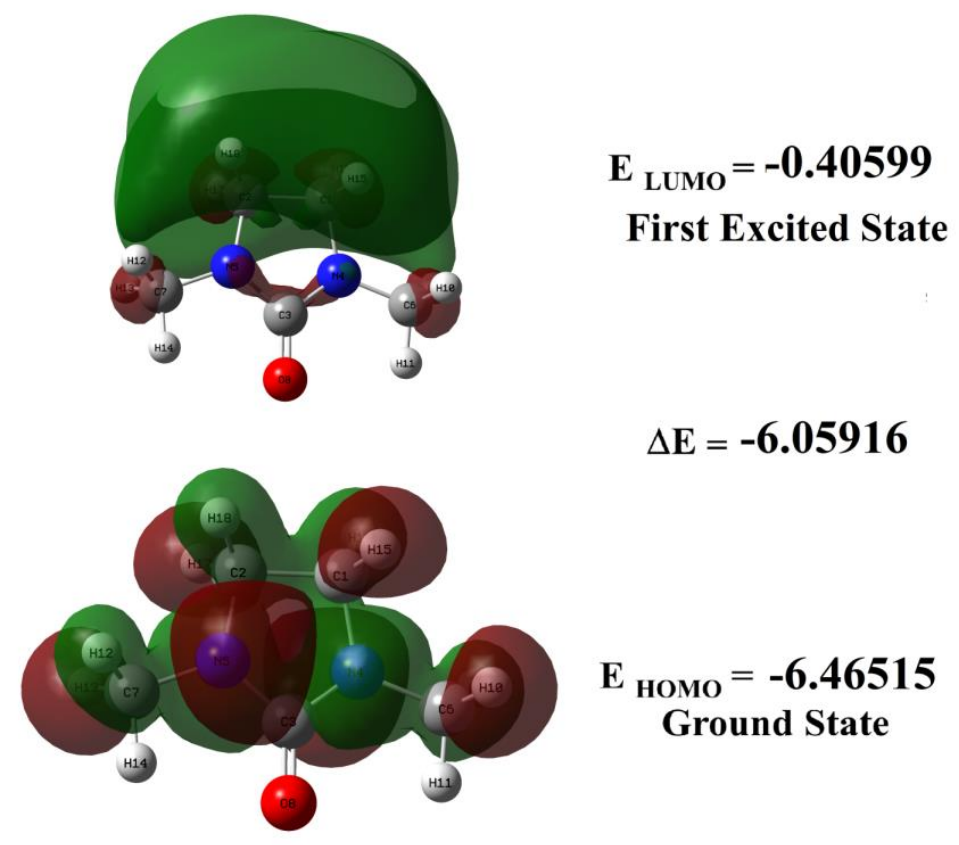

Figure 5. Ground-state (HOMO: 31) and First exited state (LUMO: 32) representation.

Table 3. The calculated quantum chemical parameters of N-N'-dimethylethylene urea.

\begin{tabular}{c|c} 
Property & NND \\
\hline Total energy $(\mathrm{eV})$ & -10378.7347 \\
\hline Eномо $(\mathrm{eV})$ & -6.4651 \\
\hline ELumo $(\mathrm{eV})$ & -0.4059 \\
\hline Energy gap $(\Delta \mathrm{E})(\mathrm{eV})$ & -6.0591 \\
\hline Ionization potential $(\mathrm{I}) \mathrm{eV}$ & 6.4651
\end{tabular}




\begin{tabular}{c|c} 
Property & NND \\
\hline Electron Affinity $(\mathrm{A}) \mathrm{eV}$ & 0.4059 \\
\hline Electro-negativity $(\chi) \mathrm{eV}$ & 6.6681 \\
\hline Chemical Potential $(\mu)$ & 3.4355 \\
\hline Chemical hardness $(\eta) \mathrm{eV}$ & 6.2621 \\
\hline Electrofilicity index $(\omega) \mathrm{eV}$ & 0.9424 \\
\hline Global Softness $(\sigma) \mathrm{eV}$ & 0.1596 \\
\hline Dipole moment $(\mathrm{D})$ & 4.1069
\end{tabular}

\subsection{NBO analysis and NLO properties.}

The interaction between the lone pair orbitals and bonded orbitals causes the stabilization of the molecule. These interactions can be well studied using the concept of natural bond orbitals. NBO calculations have been implemented in the Gaussian suite, and the data obtained helps to understand the delocalization of electrons and hyperconjugation $[41,42]$.

Table 4. Second order perturbation theory analysis of fock matrix in NBO basis for $\mathrm{N}-\mathrm{N}$ '-dimethylethylene urea.

\begin{tabular}{|c|c|c|c|c|c|c|c|c|}
\hline Donor(i) & Type & Ed/e & Acceptor(j) & Type & Ed/e & $\begin{array}{c}\mathbf{E}^{(2) a} \\
\left(k \mathrm{~mol}^{-1}\right)\end{array}$ & $\begin{array}{c}\mathbf{E}(\mathbf{i})-\mathbf{E}(\mathbf{j})^{\mathbf{b}} \\
\quad(\mathbf{a} . \mathbf{u})\end{array}$ & $\begin{array}{l}\mathbf{f}(\mathbf{i}, \mathbf{j})^{\mathrm{c}} \\
(\mathbf{a} . \mathbf{u})\end{array}$ \\
\hline \multirow[t]{2}{*}{$\mathrm{C} 1-\mathrm{C} 2$} & $\Sigma$ & 1.9779 & N4-C6 & $\sigma^{*}$ & 0.0152 & 4.04 & 0.98 & 0.056 \\
\hline & $\Sigma$ & & $\mathrm{N} 5-\mathrm{C} 7$ & $\sigma^{*}$ & 0.0152 & 4.04 & 0.98 & 0.056 \\
\hline \multirow[t]{2}{*}{ C1-N4 } & $\Sigma$ & 1.9827 & $\mathrm{C} 2-\mathrm{N} 5$ & $\sigma^{*}$ & 0.0204 & 1.19 & 1.07 & 0.032 \\
\hline & $\Sigma$ & & $\mathrm{C} 3-\mathrm{O} 8$ & $\pi^{*}$ & 0.0119 & 4.24 & 1.36 & 0.068 \\
\hline $\mathrm{C} 1-\mathrm{H} 15$ & $\Sigma$ & 1.9858 & C2-H17 & $\sigma^{*}$ & 0.0296 & 1.96 & 0.90 & 0.038 \\
\hline $\mathrm{C} 1-\mathrm{H} 16$ & $\Sigma$ & 1.9858 & C3-N4 & $\sigma^{*}$ & 0.0844 & 1.98 & 0.97 & 0.040 \\
\hline \multirow[t]{2}{*}{ C2-N5 } & $\Sigma$ & 1.9827 & C1-N4 & $\sigma^{*}$ & 0.0204 & 1.19 & 1.07 & 0.032 \\
\hline & $\Sigma$ & & C3-O8 & $\pi^{*}$ & 0.0119 & 4.24 & 1.36 & 0.068 \\
\hline C2-H17 & $\Sigma$ & 1.9858 & C1-H15 & $\sigma^{*}$ & 0.0296 & 1.96 & 0.90 & 0.038 \\
\hline C2-H18 & $\Sigma$ & 1.9858 & C3-N5 & $\sigma^{*}$ & 0.0844 & 1.98 & 0.97 & 0.040 \\
\hline \multirow[t]{2}{*}{ C3-N4 } & $\Sigma$ & 1.9831 & C3-O8 & $\pi^{*}$ & 0.0119 & 1.30 & 1.42 & 0.038 \\
\hline & $\Sigma$ & & N5-C7 & $\sigma^{*}$ & 0.0152 & 3.12 & 1.14 & 0.053 \\
\hline C3-N5 & $\Sigma$ & 1.9830 & $\mathrm{C} 3-\mathrm{O} 8$ & $\pi^{*}$ & 0.0119 & 1.30 & 1.42 & 0.038 \\
\hline \multirow[t]{2}{*}{ C3-O8 } & $\Sigma$ & 1.9948 & N4-C6 & $\sigma^{*}$ & 0.0152 & 3.12 & 1.14 & 0.053 \\
\hline & $\Sigma$ & & C3-O8 & $\sigma^{*}$ & 0.3779 & 2.20 & 0.38 & 0.029 \\
\hline \multirow[t]{2}{*}{ C3-O8 } & $\Pi$ & 1.9931 & C1-N4 & $\sigma^{*}$ & 0.0204 & 1.07 & 1.40 & 0.035 \\
\hline & $\Pi$ & & C3-N5 & $\sigma^{*}$ & 0.0844 & 1.46 & 1.49 & 0.042 \\
\hline N4-C6 & $\Sigma$ & 1.9881 & C3-N5 & $\sigma^{*}$ & 0.0844 & 1.44 & 1.18 & 0.037 \\
\hline N5-C7 & $\Sigma$ & 1.9881 & $\mathrm{C} 3-\mathrm{N} 4$ & $\sigma^{*}$ & 0.0844 & 1.44 & 1.18 & 0.0 .37 \\
\hline C6-H9 & $\Sigma$ & 1.9906 & $\mathrm{C} 3-\mathrm{N} 4$ & $\sigma^{*}$ & 0.0844 & 2.75 & 0.96 & 0.047 \\
\hline C6-H10 & $\Sigma$ & 1.9915 & $\mathrm{C} 3-\mathrm{N} 4$ & $\sigma^{*}$ & 0.0844 & 0.54 & 0.95 & 0.021 \\
\hline C6-H11 & $\Sigma$ & 1.9879 & C1-N4 & $\sigma^{*}$ & 0.0204 & 4.40 & 0.86 & 0.055 \\
\hline C7-H12 & $\Sigma$ & 1.9906 & C3-N5 & $\sigma^{*}$ & 0.0844 & 2.75 & 0.96 & 0.047 \\
\hline C7-H13 & $\Sigma$ & 1.9915 & C3-N5 & $\sigma^{*}$ & 0.0844 & 0.54 & 0.95 & 0.021 \\
\hline C7-H14 & $\Sigma$ & 1.9879 & C2-N5 & $\sigma^{*}$ & 0.0204 & 4.40 & 0.86 & 0.055 \\
\hline \multirow[t]{2}{*}{$\mathrm{N} 4$} & LP & 1.7444 & C1-H15 & $\sigma^{*}$ & 0.0296 & 7.54 & 0.64 & 0.066 \\
\hline & LP & & C3-O8 & $\sigma^{*}$ & 0.3779 & 50.63 & 0.29 & 0.111 \\
\hline \multirow[t]{2}{*}{ N5 } & LP & 1.7444 & C2-H17 & $\sigma^{*}$ & 0.0296 & 7.54 & 0.64 & 0.066 \\
\hline & LP & & C3-O8 & $\sigma^{*}$ & 0.3779 & 50.64 & 0.29 & 0.111 \\
\hline O8 & LP & 1.9781 & C3-N5 & $\sigma^{*}$ & 0.0844 & 1.85 & 1.11 & 0.041 \\
\hline O8 & LP & 1.8408 & C3-N5 & $\sigma^{*}$ & 0.0844 & 25.08 & 0.68 & 0.118 \\
\hline
\end{tabular}

a $\mathrm{E}(2)$ means energy of hyper conjugative interaction (stabilization energy).

b Energy difference between donor and acceptor i and j NBO orbitals. c $F(i, j)$ is the Fock matrix element between $i$ and $j$ NBO orbitals.

The orbital occupancy data and delocalization energy provide valuable information about the electron environment and stabilization. From the NBO analysis, stabilization energy 
is maximum for $\mathrm{n} 1(\mathrm{~N} 6) \rightarrow \pi^{*}(\mathrm{C} 3-\mathrm{O} 8), \mathrm{n}_{1}(\mathrm{~N} 5) \rightarrow \pi^{*}(\mathrm{C} 3-\mathrm{O} 8)$, and $\mathrm{n}_{1}(\mathrm{O} 8) \rightarrow \pi^{*}(\mathrm{C} 3-\mathrm{N} 5)$ with stabilization energies $50.63,50.64$ and $23.08 \mathrm{kcal} / \mathrm{mol}$ respectively. The NBO result is tabulated in Table 4.

Scientists engaged in the molecular electronics field are continuously searching for molecules with substantial nonlinear optical activity. Such compounds find immense applications in electronic display, surveillance equipment, and routine electronic gadgets. Computationally, a molecule's ability to act as an NLO material can be generated from the polarisability and hyperpolarizability data [22-28]. The electric dipole moment, first-order, and second-order polarizabilities are 2.6109 debyes, $23.65561 \times 10^{-24} \mathrm{esu}$, and $1.51451 \times 10^{-30} \mathrm{esu}$, respectively. The corresponding list of NLO properties is shown in Table 5.

Table 5. The electric dipole moment (D), average polarizability, first hyperpolarizability, etc., for N-N'dimethylethylene urea.

\begin{tabular}{|c|c|c|c|}
\hline$\mu$ and $\alpha$ components & B3LYP/6-311++G** & $\beta$ components & B3LYP/6-311++G** \\
\hline$\mu_{\mathrm{x}}$ & -0.0003 & $\beta_{\mathrm{xxx}}$ & -0.0101 \\
\hline$\mu_{\mathrm{y}}$ & 1.6157 & $\beta_{\mathrm{xxy}}$ & -64.4969 \\
\hline$\mu_{\mathrm{z}}$ & 0.000009 & $\beta_{\text {xyy }}$ & -0.0019 \\
\hline$\mu(\mathrm{D})$ & 2.6107 & $\beta_{\text {yyy }}$ & 148.3545 \\
\hline$\alpha_{x x}$ & 92.0035 & $\beta_{\mathrm{xxz}}$ & -0.0113 \\
\hline$\alpha_{x y}$ & 0.00004 & $\beta_{\mathrm{xyz}}$ & -4.3684 \\
\hline$\alpha_{\mathrm{yy}}$ & 82.7754 & $\beta_{\mathrm{yyz}}$ & -0.0081 \\
\hline$\alpha_{\mathrm{xz}}$ & 1.7840 & $\beta_{\mathrm{xzz}}$ & -0.0027 \\
\hline$\alpha_{\mathrm{yz}}$ & -0.00008 & $\beta_{\mathrm{yzz}}$ & 91.4439 \\
\hline$\alpha_{\mathrm{zz}}$ & 61.5327 & $\beta_{z z z}$ & 0.0037 \\
\hline$\Delta \alpha$ & \multicolumn{3}{|c|}{$23.6556 \times 10^{-24} \mathrm{esu}$} \\
\hline$\alpha_{0}(\mathrm{esu})$ & $11.6736 \times 10^{-24}$ & Btotal (esu) & $1.5145 \times 10^{-30}$ \\
\hline
\end{tabular}

3.5. Noncovalent interactions (NCI), reduced density gradient (RDG), and Laplacian of electron density (LED) for $N$-N'-dimethylethylene urea.

A noncovalent interaction differs from a covalent bond by not involving electrons' sharing but involving more dispersed variations of electromagnetic interactions between molecules or within a molecule [11,43-46]. The three-dimensional arrangement of large molecules, such as protein and nucleic acids, is important to noncovalent interactions. Additionally, they are also involved in many biological processes where large molecules bind to each other specifically but transiently. These interactions also have a strong impact on drug design, crystallinity and material design, self-assembly, and the design of synthesis of tailormade organic molecules. The noncovalent interactions for $\mathrm{N}-\mathrm{N}$ '-dimethylethylene urea are shown in Figure 6. A graph plotted energy (from - 0.014 to 0.042 a.u.) against a reduced density gradient (from 0.850 to 1.200 ). The strong hydrogen bonds having negative energy between the range -0.015 and -0.013 a.u. between nitrogen in imidazole- and hydrogens in $\mathrm{N}$-acetylgroups, van der Waals force attraction is a weak hydrogen bonds energy between -0.005 and 0.005 a.u. from carbonyl- oxygen to $\mathrm{N}$-acetyl- hydrogens, and steric force is a weak repulsive force of energy between the range 0.005 and 0.042 a.u. for imidazole- ring, and between carbonyl- oxygen, and $\mathrm{N}$-acetyl- groups.

The reduced density gradient is directly proportional to the molecule's electronic density, which means a small reduced density gradient is low electronic density [43,46-49]. Figure 6 shows the reduced density gradient for N-N'-dimethylethylene urea, from the blue to red as the numerical values between 0.000 and 1.000, and the molecule within $\pm 7.45 \mathrm{Bohr}^{3}$ range. The red shows the high electronic reduced density between 0.9000 and 1.000 on the 
elements between carbonyl-oxygen, and $\mathrm{N}$-acetyl- groups, and all the heavy atoms are nitrogens and carbons in the imidazole- group. The small reduced density gradients shown in color blue are low reduced densities from 0.000 to 0.200 mingle with low reduced density gradients in imidazole-ring shown in Figure 6.

The Laplacian of electron density is the absolute difference from the mean [50,51]. Figure 6 shows the Laplacian of electron density for N-N'-dimethylethylene urea., from blue to red as the numerical values between -8.000 and 15.000 , and the molecule within \pm 6.56 Bohr ${ }^{3}$ range. The blue between the ranges -5.700 and -3.400 show the negative Laplacian electron density on carbonyl-oxygen, -0.900 and 0.600 on hydrogens in $\mathrm{N}$-acetyl- groups, and electrophiles can easily attack these sites. The red in the color range between 12.700 and 15.000 shows positive Laplacian electron density on nitrogens and carbons in the molecule, so nucleophiles can easily attack these sites.
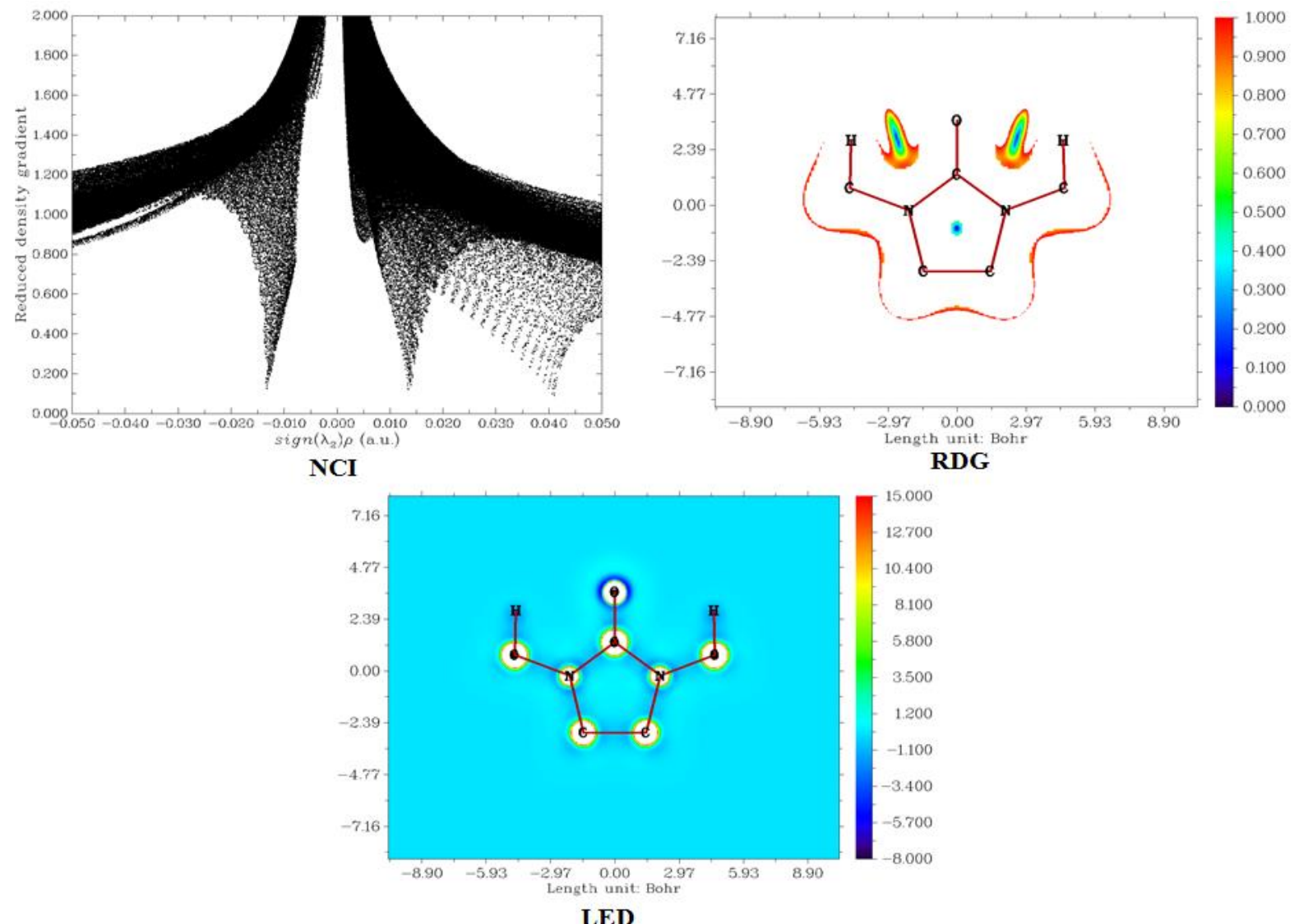

Figure 6. Noncovalent interactions, reduced density gradient, and Laplacian of electron density of N-N'dimethylethylene urea.

\subsection{Molecular electrostatic potentials (MESP) for $N$-N'-dimethylethylene urea from} electronic and molecular charges.

The electrostatic potential V(r) generated around a molecule by its nuclei and electrons treated as static charge distribution is a very useful property for studying and predicting molecular-reactive actions. This is narrowly defined and can be calculated both experimentally and computationally. The capacity has been especially useful for indicating the molecule's positions or regions to which the advancing electrophile is initially drawn. It has also been effectively extended to analyze associations requiring a certain optimal relative orientation of the reactants, such as between the product and its cellular receptor [52-55]. N- 
N'dimethylethylenurea molecule's MESP was generated using the data obtained in the previous calculation and is represented in Figure 7.

The blue appears on the oxygen, and nitrogen atoms ring (electrophilic region) in the imidazole- group, which are electron-rich sites, so electrophiles can easily attack these sites. The red color appears on all the protons in the nitrogen atoms and carbon atoms in the imidazole (nucleophilic region) group. These are electrons poor sites, so nucleophiles can easily attack these sites.

The nuclear charge between 12.500 and 15.000 are indicated by blue color, which means repulsion between protons and nuclei in the absence of neutrons as in hydrogen. These sites mostly undergo substitution reactions. The nuclear charge between 45 and 50 is indicated using red, which is negative electrostatic potential with strong attractions between protons and nuclei by core and lone-pair of electrons in heavy atoms like oxygen, nitrogen, and carbon in the molecule, and these sites mostly undergo addition reactions.
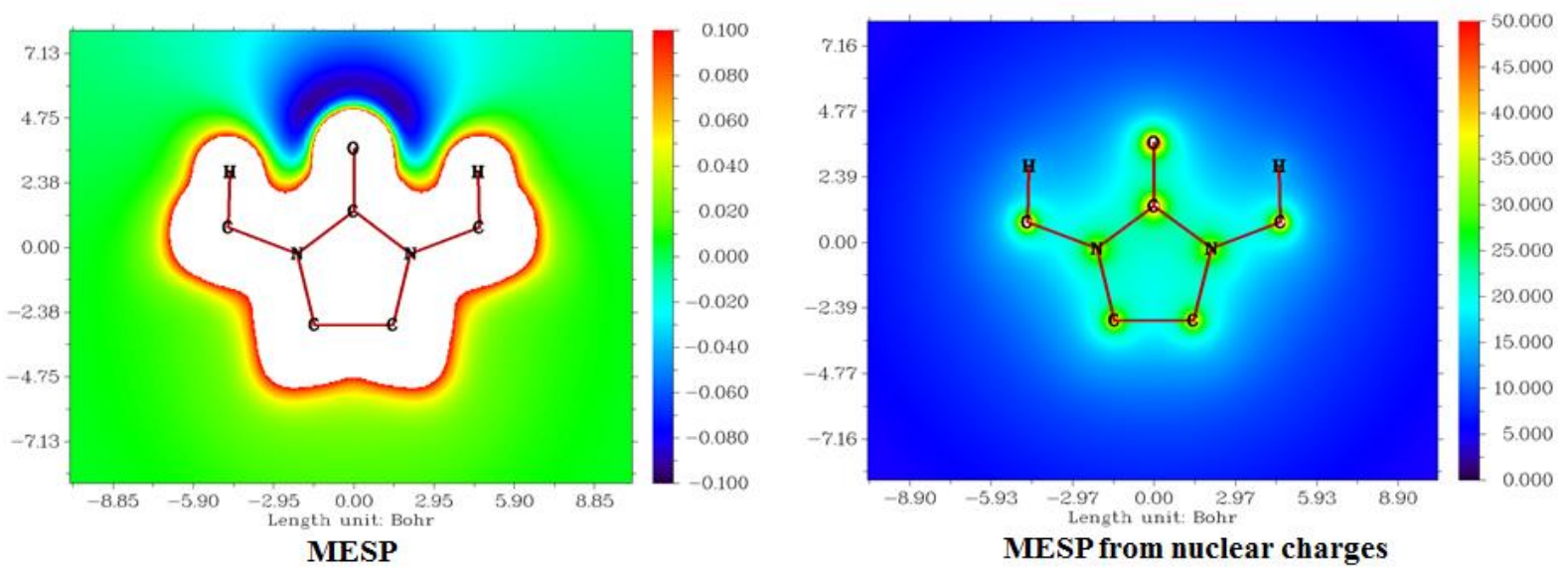

Figure 7. Molecular electrostatic potentials from electronic and nuclear charges of N-N'-dimethylethyleneurea

3.7. Electron localized function (ELF), and localized orbital locator ( $L O L)$ for $N-N$ 'dimethylethylene urea.

Electron localized function study explains further the electronic structure for N-N'dimethylethylene urea. The higher value of the electron localization function is strongly localized, and the low value is a strong delocalization of electrons in this molecule [56-58]. The electron localized function (ELF) for N-N'-dimethylethylene urea is shown in Figure 8, from blue to red as the numerical values between 0.000 and 0.100 , and the molecule within \pm 8.93 $\mathrm{Bohr}^{3}$ range. The color red between the range 0.850 and 1.000 shows the highest probability of localized electrons occurs on all the hydrogen atoms, and core electrons in heavy atoms are oxygen, nitrogens, and carbons in the molecule. The color blue between the range 0.000 and 0.200 shows the highest probability of delocalized electrons occurs in imidazolering, and valance and lone-pairs of electrons in heavy atoms are hydrogen, nitrogens, and carbons in the molecule.

The localized orbital locator (LOL) study explains the localized and delocalized molecular orbitals locations for N-N'-dimethylethylene urea [56-58]. The localized orbital locator (LOL) for N-N'-dimethylethylene urea is shown in Figure 8, from blue to red as the numerical values between 0.000 and 0.800 , and the molecule within $\pm 8.92 \mathrm{Bohr}^{3}$ range. The blue color denotes weak pi-delocalized orbital, and the red color denotes strong pi-delocalized orbitals in N-N'-dimethylethylene urea; in this molecule, these orbitals appear adjacently, so delocalization of electrons occurs on oxygen, nitrogens, and carbons in the molecule. 

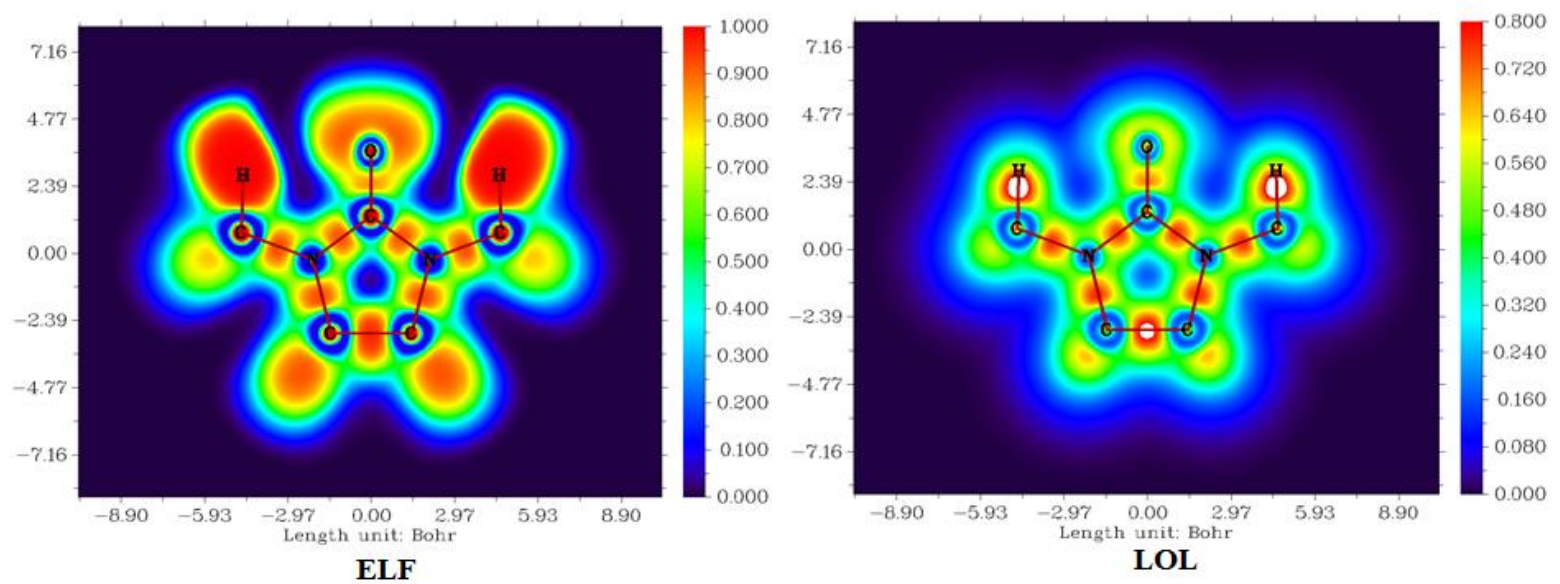

Figure 8. Electron localized function and local orbital locator of N-N'-dimethylethylene urea.

3.8. Average localized ionization energy (ALIE) and local information entropy (LIE) study for $N$-N'-dimethylethylene urea.

The local I(r) average energy of ionization is the energy needed to remove an electron from point $r$ into the system. The lowest values show the least tightly-held electrons' positions and, therefore, the chosen reaction sites with electrophiles or radicals. Beyond its importance to reactive behavior, I(r) plays a significant role in other fundamental fields, including atomic shell composition, electronegativity, local polarizability, and hardness [59-62]. The pictorial representation of ALIE of N-N'-dimethylethylene urea is given in Figure 9, from blue to red as the numerical values between 0.000 and 2.000, and the molecule within $\pm 7.34 \mathrm{Bohr}^{3}$ range. The color bluish-green range between 0.700 and 0.900 indicates moving electrons or delocalization of electrons in N-N'-dimethylethylene urea molecule at the sites are carbonyl oxygen, and acetyl- groups imidazole- group, which produce resonance structures and make the molecule stable. The blue indicates the sigma bond as well as the stable bond between carbons and hydrogens, carbon and nitrogen, and carbon and carbon, and lone-pair of electrons of carbonyl- oxygen, which the sites are from protons to carbons in the whole molecule, and lone pair of electrons having oxygens and nitrogen in purin- and methoxyphenyl- groups.
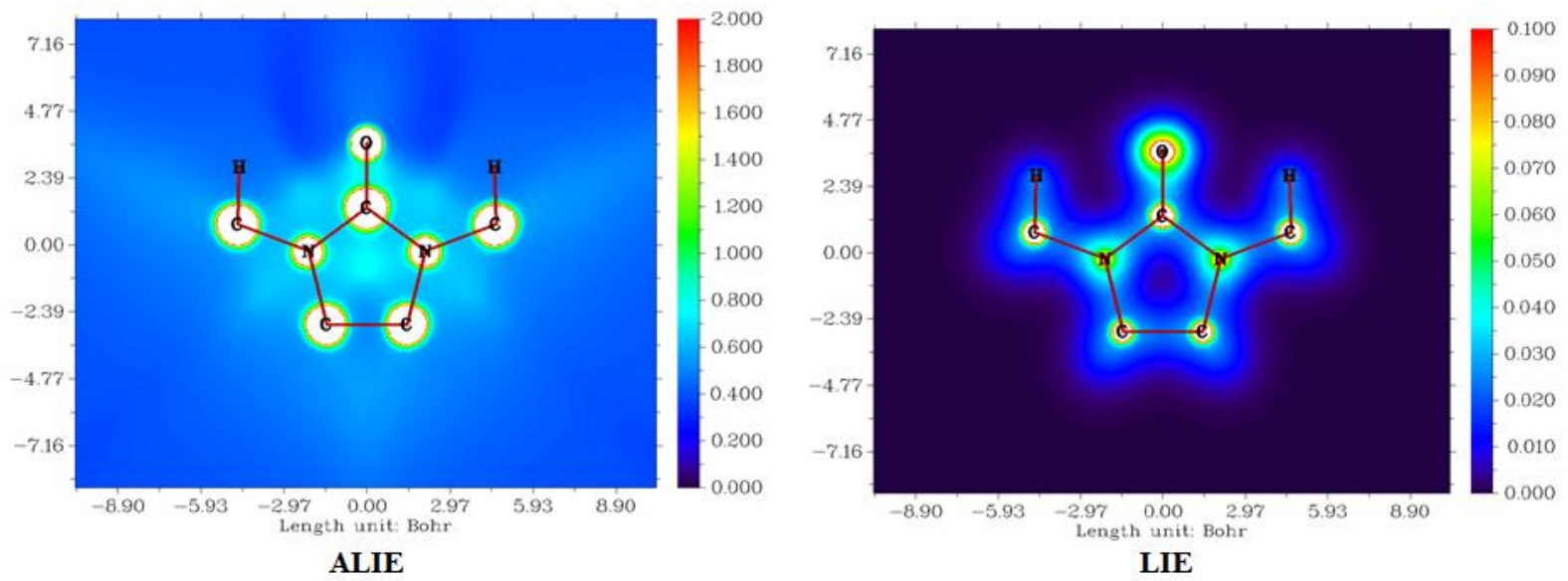

Figure 9. Average localized ionization energy and local information entropy of N-N'-dimethylethylene urea.

The local information entropy (LIE) study explains the stability of the molecule. Entropy is a feature of probability distributions and can take to be a qualification of uncertainty. The high value of local information entropy is directionally proportional to electrons' uncertainty in spatial distribution [37-40]. Figure 9 shows local information entropy for N-N'- 
dimethylethylene urea, from the blue to red as the numerical values between 0.000 and 1.000 , and the molecule within $\pm 7.45 \mathrm{Bohr}^{3}$ range. The color blue between the range 0.000 and 0.020 has low entropy values, which is explain the very low uncertainty of the elements are all the hydrogen in the molecule. The color red between the range 0.085 to 0.100 has high entropy values, which is explain high uncertainty of the heavy elements are oxygen, nitrogens, and carbons in the molecule.

\subsection{Inclusion complex with cyclodextrins.}

Biological activity prediction and molecular docking studies indicate that our compound can be developed as methylhydantoinase inhibitor for clinical applications. Drug delivery is a critical issue to be addressed when it is developed as a drug. Here, we attempt to make an active complex of the drug NND with $\gamma$-cyclodextrin (CD). The drug is placed inside the $\mathrm{CD}$ and optimized to a minimum. As the complex formation involves bulky molecules, there is a possibility of dispersion interactions; hence we have incorporated the dispersion corrections to the B3LYP functional using Grimme's dispersion correction using 6-31G (d) basis set [63-67]. The data presented in Table 6 indicates that dispersion is a significant factor to be considered while modeling molecular inclusion systems. The dispersion energy for the complex is $9.09 \mathrm{kcal} / \mathrm{mol}$, which is an appreciable amount of energy that confirms that appreciable dispersion interaction exists in the complex, as expected. The optimized geometry of the complex is provided in Figure 10. The distance between the carbonyl oxygen of NND and the nearest hydrogen atom of the $\mathrm{CD}$ in the complex is 2.5863A. Furthermore, to investigate the driving forces of NND in $\gamma$-CD, we have calculated the complexation energy, HOMO, and LUMO energies, chemical reactivity defined as per the following equation.

$$
\Delta \mathrm{E}_{\text {complexation }}=\mathrm{E}^{\mathrm{opt}} \text { complex }-\left[\mathrm{E}(\gamma-\mathrm{CD})^{\mathrm{opt}}{ }_{\text {free }}+\mathrm{E}(\mathrm{NND})\right]^{\mathrm{opt}} \text { free }
$$

From the data, the complexation energy is found to be $-56.4949791 \mathrm{kcal} / \mathrm{mol}$, which is appreciable energy.

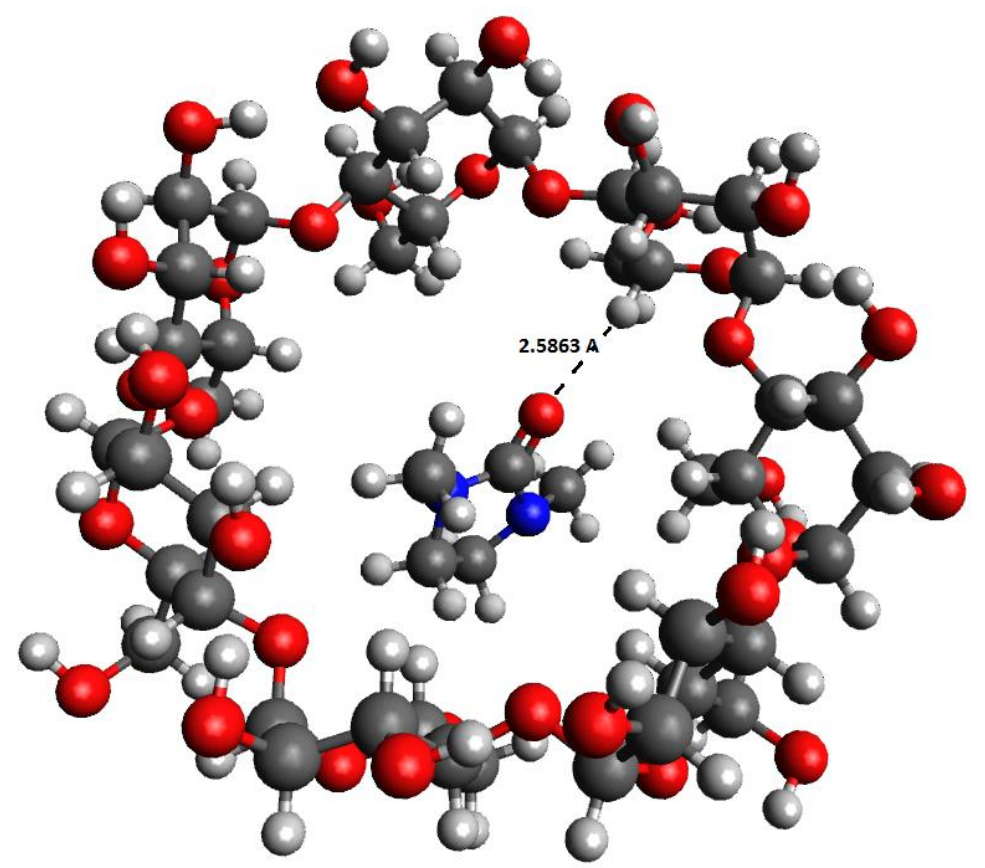

Figure 10. NND- CD complex optimized at B3LYP/6-31G(d) with Griumme's dispersion correction. 
Table 6. Molecular recognition energy between NND and CD with and without dispersion correction.

\begin{tabular}{c|c|c} 
System & B3LYP/6-31G(d) & $\begin{array}{c}\text { B3LYP/6-31G(d) with } \\
\text { Grimme's dispersion } \\
\text { correction }\end{array}$ \\
\hline NND & -381.1799371 & -381.1925119 \\
\hline$\gamma$-cyclodextrin & -4275.18 & -4275.42 \\
\hline NND-CD Complex & -4656.435218 & -4656.702187 \\
\hline Energy of Inclusion & -0.07528082 & -0.08967457 \\
\hline$(\mathrm{kcal} / \mathrm{mol})$ & -47.4269166 & -56.4949791
\end{tabular}

\subsection{Molecular docking studies of NND.}

The biological activity of NND was shown in Table 7 from the PASS online site. Nmethylhydantoinase (ATP-hydrolysing) inhibitor has the topmost probability of being active with a very low probability of inactive values corresponding PDB ID: 3 I73 [68] downloaded and prepared to dock undock with NND molecule by both online servers SwissDock and PatchDock. The result from the SwissDock server shown in Table 8 explains full fitness energy $-2675.96 \mathrm{kcal} / \mathrm{mol}$, total $\Delta \mathrm{G}$ energy $-5.89 \mathrm{kcal} / \mathrm{mol}$, as well as inter full fitness, intra full fitness, full solvent fitness, full surface fitness, $\Delta \mathrm{G}$ of complex solvent polar, complex solvent nonpolar, protein solvent polar, protein solvent non-polar, ligand solvent polar, ligand solvent nonpolar, van der Waals force and electrical fore energies for interactions between NND and protein with the unit of $\mathrm{kcal} / \mathrm{mol}$.

Table 7. Biological activity prediction of NND using PASS.

\begin{tabular}{c|c|c}
$\mathbf{P a}$ & $\mathbf{P i}$ & Activity \\
\hline 0.87 & 0.002 & N-methylhydantoinase (ATP-hydrolysing) inhibitor \\
\hline 0.87 & 0.004 & Nicotinic alpha6beta3beta4alpha5 receptor antagonist \\
\hline 0.865 & 0.004 & Nicotinic alpha2beta2 receptor antagonist \\
\hline 0.844 & 0.015 & Testosterone 17beta-dehydrogenase (NADP+) inhibitor \\
\hline 0.845 & 0.018 & Phobic disorders treatment \\
\hline 0.815 & 0.004 & Phospholipid-translocating ATPase inhibitor \\
\hline 0.807 & 0.012 & Glycosylphosphatidylinositol phospholipase D inhibitor \\
\hline 0.791 & 0.003 & Kidney function stimulant \\
\hline 0.797 & 0.013 & NADPH peroxidase inhibitor
\end{tabular}

Table 8. Thermodynamic data from molecular docking.

\begin{tabular}{c|c} 
Full Fitness & $-2675.964 \mathrm{kcal} / \mathrm{mol}$ \\
\hline Inter Full Fitness & $-20.2328 \mathrm{kcal} / \mathrm{mol}$ \\
\hline Intra Full Fitness & $-28.1168 \mathrm{kcal} / \mathrm{mol}$ \\
\hline Solvent Full Fitness & $-2984.41 \mathrm{kcal} / \mathrm{mol}$ \\
\hline Surface Full Fitness & $356.796 \mathrm{kcal} / \mathrm{mol}$ \\
\hline Extra Full Fitness & $0 \mathrm{kcal} / \mathrm{mol}$ \\
\hline$\Delta \mathrm{G}$ complex solvent polar & $-2984.41 \mathrm{kcal} / \mathrm{mol}$ \\
\hline$\Delta \mathrm{G}$ complex solvent non- & $356.796 \mathrm{kcal} / \mathrm{mol}$ \\
\hline polar & $-2985.62 \mathrm{kcal} / \mathrm{mol}$ \\
\hline$\Delta \mathrm{G}$ protein solvent polar & $357.709 \mathrm{kcal} / \mathrm{mol}$ \\
\hline$\Delta \mathrm{G}$ protein solvent non-polar & $-6.44042 \mathrm{kcal} / \mathrm{mol}$ \\
\hline$\Delta \mathrm{G}$ ligand solvent polar & $3.93924 \mathrm{kcal} / \mathrm{mol}$ \\
\hline$\Delta \mathrm{G} \mathrm{ligand} \mathrm{solvent} \mathrm{non-polar}$ & $-20.2328 \mathrm{kcal} / \mathrm{mol}$ \\
\hline$\Delta \mathrm{G}$ van der Waals fore & $0 \mathrm{kcal} / \mathrm{mol}$ \\
\hline$\Delta \mathrm{G}$ electrical force & $-5.894829 \mathrm{kcal} / \mathrm{mol}$
\end{tabular}

The result from PatchDock having the score value 2656, area $287.20(\AA)^{2}$ and minimum atomic contact energy $-79.28 \mathrm{kcal} / \mathrm{mol}$ between NND and referred protein. The BioDiscovery 
Studio 2017 software is used for interpreting interactions between NND and protein $[14,15,69$ 75].

3.10.1. Interactions between NND and protein.

Figure 11 shows skeletal structure interactions between NND and protein residues with the types and bond distances, and Figure 12 interactions between NND and protein residues with the label. Table 9 explains all types of interacting protein residues with NND having hydrophobicity value, average isotropic displacement, secondary structure, residue solvent accessibility, sidechain solvent accessibility, percent solvent accessibility, and percent sidechain solvent accessibility. Table 10 explains the favorable non-bond interaction category, type, chemistry, and bond distances between NND and protein residues. There are also unsatisfied bond oxygen atoms in the NND molecule.

Figure S1 and Table 9 explain hydrophobic interactions between NND and protein residues. Figure S2 and Table 9 explain hydrophilic and acidic group interactions between NND and protein residues. There is no basic group interaction between NND and protein. Figure S3 and Table 9 explain neutral group interactions between NND and protein residues [76-84].

Table 9. Interactions between NND and protein residues.

\begin{tabular}{|c|c|c|c|c|c|c|c|c|}
\hline Name & Label & Hydrophobicity & $\begin{array}{c}\text { Average } \\
\text { Isotropic } \\
\text { Displacement } \\
(\AA)^{2}\end{array}$ & $\begin{array}{c}\text { Secondary } \\
\text { structure }\end{array}$ & $\begin{array}{l}\text { Residue Solvent } \\
\text { Accessibility }(\AA)^{2}\end{array}$ & $\begin{array}{c}\text { Sidechain } \\
\text { Solvent } \\
\text { Accessibility }(\AA)^{2}\end{array}$ & $\begin{array}{l}\text { Percent Solvent } \\
\text { Accessibility }(\AA)^{2}\end{array}$ & $\begin{array}{c}\text { Percent } \\
\text { sidechain } \\
\text { Solvent } \\
\text { Accessibility } \\
(\AA)^{2}\end{array}$ \\
\hline Isoleucine & A:Ile84 & 4.5 & 65.899 & Sheet & 47.513 & 40.757 & 29.737 & 35.92 \\
\hline Leucine & A:Leu92 & 3.8 & 94.684 & Sheet & 114.885 & 97.113 & 75.734 & 97.722 \\
\hline $\begin{array}{l}\text { Glutamic } \\
\text { Acid }\end{array}$ & A:Glu93 & $-3.5(\mathrm{pKa} 4.3)$ & 99.926 & Coil & 140.977 & 110.988 & 79.933 & 89.926 \\
\hline $\begin{array}{c}\text { Methionin } \\
\mathrm{e} \\
\end{array}$ & A:Met268 & 1.9 & 113.007 & Turn & 86.602 & 69.606 & 47.593 & 53.951 \\
\hline Valine & A:Val271 & 4.2 & 110.919 & Turn & 49.28 & 48.808 & 35.043 & 55.508 \\
\hline Leucine & A:Leu272 & 3.8 & 109.171 & Turn & 91.698 & 86.044 & 60.449 & 86.582 \\
\hline Alanine & A:Ala295 & 1.8 & 67.386 & Coil & 23.13 & 21.133 & 23.103 & 45.902 \\
\hline Threonine & A:Thr297 & -0.7 & 75.843 & Coil & 27.507 & 17.611 & 20.745 & 20.411 \\
\hline $\begin{array}{l}\text { Methionin } \\
\text { e }\end{array}$ & A:Met300 & 1.9 & 79.882 & Coil & 100.457 & 31.465 & 55.207 & 24.388 \\
\hline
\end{tabular}

Table 10. Favorable non-bond between NND and protein residues.

\begin{tabular}{c|c|c|c|c|c|c}
\multirow{2}{*}{ Distance $(\mathbf{A})$} & Category & Type & From & $\begin{array}{c}\text { From } \\
\text { Chemistry }\end{array}$ & To & To \\
& Chemistry \\
\hline 2.76967 & $\begin{array}{c}\text { Hydrogen } \\
\text { Bond }\end{array}$ & Carbon Hydrogen Bond & :UNK0:H & H-Donor & A:MET268:O & H-Acceptor \\
\hline 2.62026 & $\begin{array}{c}\text { Hydrogen } \\
\text { Bond }\end{array}$ & Carbon Hydrogen Bond & :UNK0:H & H-Donor & A:GLU93:OE2 & H-Acceptor \\
\hline 4.37675 & Hydrophobic & Alkyl & A:ALA295 & Alkyl & :UNK0 & Alkyl \\
\hline 4.46229 & Hydrophobic & Alkyl & A:ALA295 & Alkyl & :UNK0:C & Alkyl \\
\hline 3.99483 & Hydrophobic & Alkyl & :UNK0:C & Alkyl & A:LEU92 & Alkyl \\
\hline 4.41282 & Hydrophobic & Alkyl & :UNK0:C & Alkyl & A:VAL271 & Alkyl \\
\hline 2.76967 & $\begin{array}{c}\text { Hydrogen } \\
\text { Bond }\end{array}$ & Carbon Hydrogen Bond & :UNK0:H & H-Donor & A: MET268: O & H-Acceptor \\
\hline 2.62026 & $\begin{array}{c}\text { Hydrogen } \\
\text { Bond }\end{array}$ & Carbon Hydrogen Bond & $: U N K 0: H$ & H-Donor & A:GLU93:OE2 & H-Acceptor \\
\hline 4.37675 & Hydrophobic & Alkyl & A:ALA295 & Alkyl & :UNK0 & Alkyl \\
\hline 4.46229 & Hydrophobic & Alkyl & A:ALA295 & Alkyl & :UNK0:C & Alkyl \\
\hline https://biointerfaceresearch.com/ & & & & & 4009
\end{tabular}




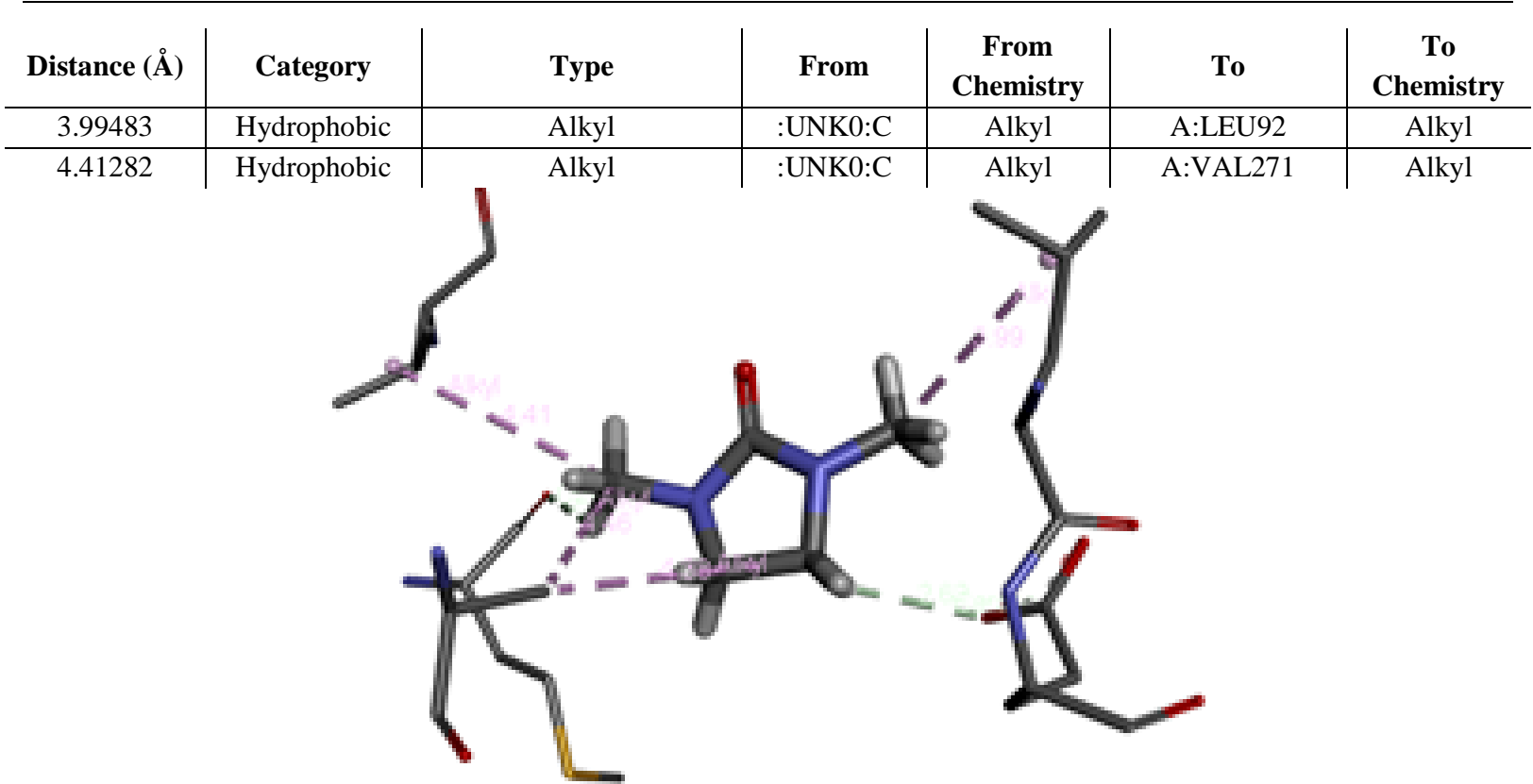

Figure 11. Skeletal structural interactions between $\mathrm{N}-\mathrm{N}$-dimethylethylene urea and protein.
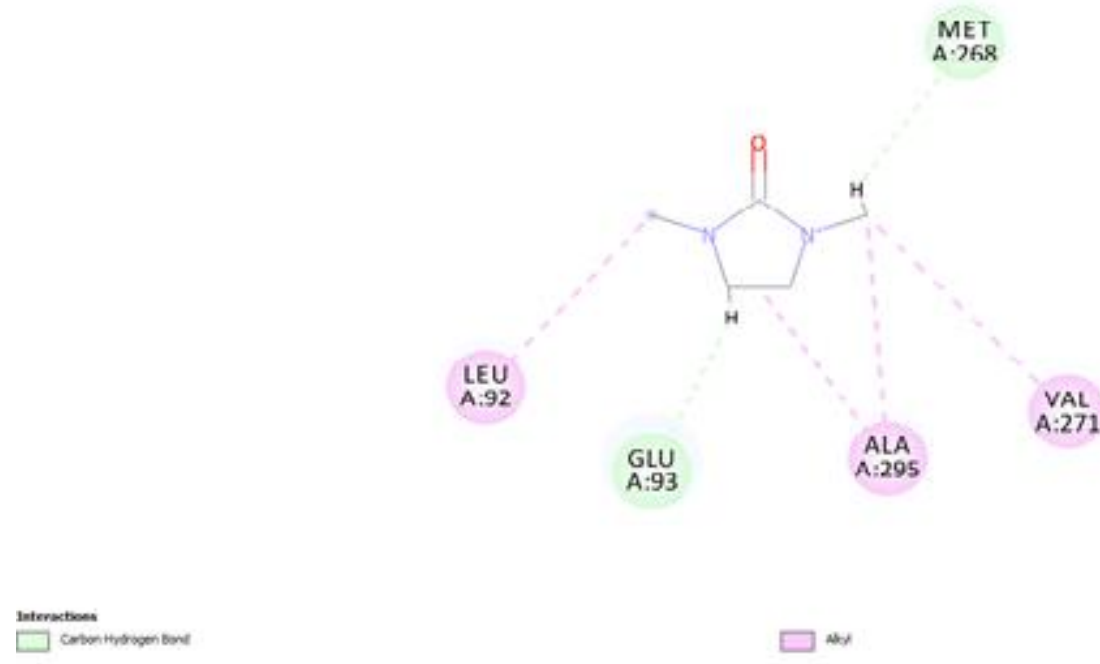

Figure 12. Interactions between $\mathrm{N}-\mathrm{N}^{\prime}$-dimethylethylene urea and protein residues.

\section{Conclusions}

$\mathrm{N}-\mathrm{N}$-dimethylethylene urea was characterized by IR, Raman, and UV-Vis spectra. The simulated and experimental spectra showed a close correlation. Vibrational modes are assigned based on the PED matrix. Scaled wave numbers are in good agreement with experimental wave numbers. The compound is stabilized by various intramolecular interactions and shows excellent hyperpolarizabilities indicating that it could be a potential NLO material. All electron descriptor analyses are in conformation with the reactivity details. Docking studies indicate that the molecule can be used as a methylhydantoinase (ATP-hydrolysing) inhibitor. The inclusion energy data shows that the molecule can be placed inside the cavity of a cyclodextrin molecule.

\section{Funding}

A. Irfan extends his appreciation to the Deanship of Scientific Research at King Khalid University Saudi Arabia through General Research Project under grant number (GRP/17/42). 


\section{Acknowledgments}

A. Irfan extends his appreciation to the Deanship of Scientific Research at King Khalid University Saudi Arabia through General Research Project under grant number (GRP/17/42).

\section{Conflicts of Interest}

The authors declare no conflicts of interest.

\section{References}

1. Finar, I. L. Organic Chemistry, 6th ed.; Great Britain by Richard Clay and Company, Ltd., Bungay, Suffolk, 1961.

2. Bruno, O.; Brullo, C.; Bondavalli, F.; Schenone, S.; Ranise, A.; Arduino, N.; Bertolotto, M. B.; Montecucco, F.; Ottonello, L.; Dallegri, F.; Tognolini, M.; Ballabeni, V.; Bertoni, S.; Barocelli, E.; Farmaceutiche, S.; Uni, V.; Xv, V. B.; Interna, M.; Uni, V. Synthesis and Biological Evaluation of N -Pyrazolyl- N ' -Alkyl / Benzyl / Phenylureas : A New Class of Potent Inhibitors of Interleukin 8-Induced Neutrophil Chemotaxis. J. Med. Chem. 2007, 50, 3618-3626. https://doi.org/10.1021/jm0704402.

3. Jose N. Domınguez; Caritza Leon; Juan Rodrigues; Neira Gamboa de Domınguez; Jiri Gut, P. J. R. Synthesis and Evaluation of New Antimalarial Phenylurenyl Chalcone Derivatives. J. Med. Chem. 2005, 48, 36543658. https://doi.org/10.1021/jm058208o.

4. Sahlberg, C.; Norren, R.; Engelhardt, P.; Hrgberg, M.; Kangasmets, J.; Vrang, L.; Zhang, H.; Ab, M.; Huddinge, S. Synthesis and Anti-HIV Activities of Urea-PETT Analogs Belonging to a New Class of Potent Non- Nucleoside HIV-1 Reverse Transcriptase Inhibitors. Bioorg. Med. Chem. Lett. 1998, 8, 1511-1516. https://doi.org/10.1016/S0960-894X(98)00249-2.

5. Mustafa, S.; Perveen, S.; Khan, A. Synthesis, Enzyme Inhibition and Anticancer Investigations of Unsymmetrical 1,3-disubstituted Ureas. J. Serbian Chem. Soc. 2014, 79, 1-10. https://doi.org/10.2298/JSC121212076M.

6. Kim, I.; Morisseau, C.; Watanabe, T.; Hammock, B. D. Design, Synthesis , and Biological Activity of 1, 3-Disubstituted Ureas as Potent Inhibitors of the Soluble Epoxide Hydrolase of Increased Water Solubility. J. Med. Chem. 2004, 47, 2110-2122. https://doi.org/10.1021/jm030514j

7. Shaaban, I. A. Conformational Analysis, Infrared/Raman Spectral Assignment, and Electronic Structural Studies of 1,3-Dimethyl-2-Imidazolidinone Using Quantum Chemical Calculations. J. Mol. Struct. 2019, 1175, 708-720. https://doi.org/10.1016/j.molstruc.2018.08.015.

8. Alharthi, F. A.; Al-Zaqri, N.; Alsalme, A.; Al-Taleb, A.; Pooventhiran, T.; Thomas, R.; Rao, D. J. ExcitedState Electronic Properties, Structural Studies, Noncovalent Interactions, and Inhibition of the Novel Severe Acute Respiratory Syndrome Coronavirus 2 Proteins in Ripretinib by First-Principle Simulations. J. Mol. Liq. 2021, 324, 115134. https://doi.org/10.1016/j.molliq.2020.115134.

9. Ullah, Z.; Thomas, R. Markovnikov versus Anti-Markovnikov Addition and $\mathrm{C}-\mathrm{H}$ Activation: $\mathrm{Pd}-\mathrm{Cu}$ Synergistic Catalysis. Appl. Organomet. Chem. 2021, 35, e6077. https://doi.org/10.1002/aoc.6077.

10. Alsalme, A.; Pooventhiran, T.; Al-Zaqri, N.; Rao, D. J.; Thomas, R. Structural, Physico-Chemical Landscapes, Ground State and Excited State Properties in Different Solvent Atmosphere of Avapritinib and Its Ultrasensitive Detection Using SERS/GERS on Self-Assembly Formation with Graphene Quantum Dots. J. Mol. Liq. 2021, 322, 114555. https://doi.org/10.1016/j.molliq.2020.114555.

11. Al-Zaqri, N.; Pooventhiran, T.; Rao, D. J.; Alsalme, A.; Warad, I.; Thomas, R. Structure, Conformational Dynamics, Quantum Mechanical Studies and Potential Biological Activity Analysis of Multiple Sclerosis Medicine Ozanimod. J. Mol. Struct. 2021, 1227, 129685. https://doi.org/10.1016/j.molstruc.2020.129685.

12. Al-Otaibi, J. S.; Mary, Y. S.; Armaković, S.; Thomas, R. Hybrid and Bioactive Cocrystals of Pyrazinamide with Hydroxybenzoic Acids: Detailed Study of Structure, Spectroscopic Characteristics, Other Potential Applications and Noncovalent Interactions Using SAPT. J. Mol. Struct. 2020, 1202, 127316. https://doi.org/10.1016/j.molstruc.2019.127316.

13. Al-Otaibi, J. S.; Almuqrin, A. H.; Sheena Mary, Y.; Mary, Y. S.; Thomas, R. Modeling the Conformational Preference, Spectral Analysis and Other Quantum Mechanical Studies on Three Bioactive Aminobenzoate Derivatives and Their SERS Active Graphene Complexes. Polycycl. Aromat. Compd. 2020, 1-11. https://doi.org/10.1080/10406638.2020.1827270.

14. Haruna, K.; Kumar, V. S.; Armaković, S. J.; Armaković, S.; Mary, Y. S.; Thomas, R.; Popoola, S. A.; 
Almohammedi, A. R.; Roxy, M. S.; Al-Saadi, A. A. Spectral Characterization, Thermochemical Studies, Periodic SAPT Calculations and Detailed Quantum Mechanical Profiling Various Physico-Chemical Properties of 3, 4-Dichlorodiuron. Spectrochim. Acta Part A Mol. Biomol. Spectrosc. 2020, 228, 117580. https://doi.org/10.1016/j.saa.2019.117580.

15. Al-Otaibi, J. S.; Almuqrin, A. H.; Mary, Y. S.; Mary, Y. S.; Thomas, R. Cocrystals of Hydrochlorothiazide with Picolinamide, Tetramethylpyrazine and Piperazine: Quantum Mechanical Studies, Docking and Modelling of the Photovoltaic Efficiency for DSSC. J. Mol. Model. 2020, 26, 256. https://doi.org/10.1007/s00894-020-04528-9.

16. Kanchana, U. S.; Diana, E. J.; Mathew, T. V; Anilkumar, G. Cyclodextrin Based Palladium Catalysts for Suzuki Reaction: An Overview. Carbohydr. Res. 2020, 489, 107954. https://doi.org/10.1016/j.carres.2020.107954.

17. Diana, E. J.; Kanchana, U. S.; Mathew, T. V; Anilkumar, G. Recent Developments in the Metal Catalysed Cross-Coupling Reactions for the Synthesis of the Enone System of Chalcones. Appl. Organomet. Chem. 2020, 34, e5987. https://doi.org/10.1002/aoc.5987.

18. Jose, D. E.; Kanchana, U. S.; Mathew, T. V; Anilkumar, G. Recent Studies in Suzuki-Miyaura CrossCoupling Reactions with the Aid of Phase Transfer Catalysts. J. Organomet. Chem. 2020, 927, 121538. https://doi.org/10.1016/j.jorganchem.2020.121538.

19. Kanchana, U. S.; Diana, E. J.; Mathew, T. V; Anilkumar, G. Palladium-Catalyzed Cross-Coupling Reactions of Coumarin Derivatives: An Overview. Appl. Organomet. Chem. 2020, 34 (12), e5983. https://doi.org/10.1002/aoc.5983.

20. Jose, D. E.; Kanchana, U. S.; Mathew, T. V.; Anilkumar, G. Recent Developments and Perspectives in the C-Se Cross Coupling Reactions. Current Organic Chemistry. 2020, 24, 1230-1262. http://dx.doi.org/10.2174/1385272824999200528130131.

21. Kanchana, U. S.; Mathew, T. V; Anilkumar, G. Recent Advances and Prospects in the Nickel- Catalyzed Cyanation. J. Organomet. Chem. 2020, 920, 121337. https://doi.org/10.1016/j.jorganchem.2020.121337.

22. M. J. Frisch, G. W. Trucks, H. B. Schlegel, G. E. Scuseria, M. A. Robb, J. R. Cheeseman, G. Scalmani, V. Barone, G. A. Petersson, H. Nakatsuji, X. Li, M. Caricato, A. Marenich, J. Bloino, B. G. Janesko, R. Gomperts, B. Mennucci, H. P. Hratchian, J. V. Ort, D. J. F. Gaussian09W Revision D.01. Gaussian, Inc., Wallingford CT, 2016. 2009.

23. Becke, A. D. Density-Functional Exchange-Energy Approximation with Correct Asymptotic Behavior. Phys. Rev. A 1988, 38, 3098. https://doi.org/10.1103/PhysRevA.38.3098.

24. Becke, A. D. A New Mixing of Hartree-Fock and Local Density-Functional Theories. J. Chem. Phys. 1993, 98, 1372-1377. https://doi.org/10.1063/1.464304.

25. Becke, A. D.; Johnson, E. R. A Density-Functional Model of the Dispersion Interaction. J. Chem. Phys. 2005, 123, 154101. https://doi.org/10.1063/1.2065267.

26. Becke, A. D. Perspective: Fifty Years of Density-Functional Theory in Chemical Physics. J. Chem. Phys. 2014, 140, 18A301. https://doi.org/10.1063/1.4869598.

27. Becke, A. D. Density-functional Thermochemistry. III. The Role of Exact Exchange. J. Chem. Phys. 1993, 98, 5648-5652. https://doi.org/10.1063/1.464913.

28. Krishnan, R.; Binkley, J. S.; Seeger, R.; Pople, J. A. Self-consistent Molecular Orbital Methods. XX. A Basis Set for Correlated Wave Functions. J. Chem. Phys. 1980, 72, 650-654. https://doi.org/10.1063/1.438955.

29. Longuet-Higgins, H. C.; Pople, J. A. Electronic Spectral Shifts of Non-polar Molecules in Non-polar Solvents. J. Chem. Phys. 1957, 27, 192-194. https://doi.org/10.1063/1.1743666.

30. Frisch, M. J.; Pople, J. A.; Binkley, J. S. Self-consistent Molecular Orbital Methods 25. Supplementary Functions for Gaussian Basis Sets. J. Chem. Phys. 1984, 80, 3265-3269. https://doi.org/10.1063/1.447079.

31. Rassolov, V. A.; Ratner, M. A.; Pople, J. A.; Redfern, P. C.; Curtiss, L. A. 6-31G* Basis Set for Third-Row Atoms. J. Comput. Chem. 2001, 22, 976-984. https://doi.org/10.1002/jcc.1058.

32. Friesner, R. A. Ab Initio Quantum Chemistry: Methodology and Applications. Proc. Natl. Acad. Sci. U. S. A. 2005, 102, 6648-6653. https://doi.org/10.1073/pnas.0408036102.

33. ED Glendening, AE Reed, JE Carpenter, F. W. NBO 3.1. Theoretical Chemistry Institute, University of Wisconsin, Madison 2003.

34. O’boyleO'boyle, N. M.; Tenderholt, A. L.; Langner, K. M. CCLIB: A Library for Package-Independent Computational Chemistry Algorithms. J. Comput. Chem. 2008, 29, 839-845. https://doi.org/10.1002/jcc.20823.

35. Lu, T.; Chen, F. Multiwfn: A Multifunctional Wavefunction Analyzer. J. Comput. Chem. 2012, 33, 580- 
592. https://doi.org/10.1002/jcc.22885.

36. Lagunin, A.; Stepanchikova, A.; Filimonov, D.; Poroikov, V. PASS: Prediction of Activity Spectra for Biologically Active Substances. Bioinformatics $\quad$ 2000, $16, \quad 747-748$. https://doi.org/10.1093/bioinformatics/16.8.747.

37. Hajji, M.; Mtiraoui, H.; Amiri, N.; Msaddek, M.; Guerfel, T. Crystallographic and First-Principles Density Functional Theory Study on the Structure, Noncovalent Interactions, and Chemical Reactivity of 1,5Benzodiazepin-2-Ones Derivatives. Int. J. Quantum Chem. 2019, 119 , 1-13. https://doi.org/10.1002/qua.26000.

38. Schneidman-Duhovny, D.; Inbar, Y.; Nussinov, R.; Wolfson, H. J. PatchDock and SymmDock: Servers for Rigid and Symmetric Docking. Nucleic Acids Res. 2005, 33, W363-W367. https://doi.org/10.1093/nar/gki481.

39. Mashiach, E.; Schneidman-Duhovny, D.; Peri, A.; Shavit, Y.; Nussinov, R.; Wolfson, H. J. An Integrated Suite of Fast Docking Algorithms. Proteins Struct. Funct. Bioinforma. 2010, 78, 3197-3204. https://doi.org/10.1002/prot.22790.

40. Discovery Studio BIOVA. Discovery Studio Client v17, San Diego, Dassault Systems. Dassault Systems: SanDeigio 2017

41. Reed, A. E.; Curtiss, L. A.; Weinhold, F. Intermolecular Interactions from a Natural Bond Orbital, DonorAcceptor Viewpoint. Chem. Rev. 1988, 88, 899-926. https://doi.org/10.1021/cr00088a005.

42. Weinhold, F. Natural Bond Orbital Analysis: A Critical Overview of Relationships to Alternative Bonding Perspectives. J. Comput. Chem. 2012, 33, 2363-2379. https://doi.org/10.1002/jcc.23060.

43. Boto, R. A.; Piquemal, J. P.; Contreras-García, J. Revealing Strong Interactions with the Reduced Density Gradient: A Benchmark for Covalent, Ionic and Charge-Shift Bonds. Theor. Chem. Acc. 2017, 136, 1-9. https://doi.org/10.1007/s00214-017-2169-9.

44. Karshikoff, A. Non-Covalent Interactions in Proteins; World Scientific Publishing Co., 2006. https://doi.org/10.1142/p477.

45. Pooventhiran, T.; Bhattacharyya, U.; Rao, D. J.; Chandramohan, V.; Karunakar, P.; Irfan, A.; Mary, Y. S.; Thomas, R. Detailed Spectra, Electronic Properties, Qualitative Non-Covalent Interaction Analysis, Solvatochromism, Docking and Molecular Dynamics Simulations in Different Solvent Atmosphere of Cenobamate. Struct. Chem. 2020, 31, 247502485. https://doi.org/10.1007/s11224-020-01607-8.

46. Alsalme, A.; Pooventhiran, T.; Al-Zaqri, N.; Rao, D. J.; Thomas, R. Structural, Physico-Chemical Landscapes, Ground State and Excited State Properties in Different Solvent Atmosphere of Avapritinib and Its Ultrasensitive Detection Using SERS/GERS on Self-Assembly Formation with Graphene Quantum Dots. J. Mol. Liq. 2020, 322, 114555. https://doi.org/10.1016/j.molliq.2020.114555.

47. Zupan, A.; Perdew, J. P.; Burke, K.; Causà, M. Density-Gradient Analysis for Density Functional Theory: Application to Atoms. Int. J. Quantum Chem. 1998, 61, 835-845. https://doi.org/10.1002/(SICI)1097461X(1997)61:5<835::AID-QUA9>3.0.CO;2-X.

48. Del Campo, J. M.; Gázquez, J. L.; Alvarez-Mendez, R. J.; Vela, A. The Reduced Density Gradient in Atoms. Int. J. Quantum Chem. 2012, 112, 3594-3598. https://doi.org/10.1002/qua.24241.

49. Albrecht, L.; Chowdhury, S.; Boyd, R. J. Hydrogen Bond Cooperativity in Water Hexamers: Atomic Energy Perspective of Local Stabilities. J. Phys. Chem. A 2013, 117, 10790-10799. https://doi.org/10.1021/jp407371c.

50. Jacobsen, H. Localized-Orbital Locator (LOL) Profiles of Chemical Bonding. Can. J. Chem. 2008, 86, 695702. https://doi.org/10.1139/v08-052.

51. Rizwana, F.; Prasana; Christian, J.; Muthu, S.; Abraham, C. S. Molecular Docking Studies, Charge Transfer Excitation and Wave Function Analyses (ESP, ELF, LOL) on Valacyclovir: A Potential Antiviral Drug. Comput. Biol. Chem. 2019, 78, 9-17. https://doi.org/10.1016/j.compbiolchem.2018.11.014.

52. Breneman, C. M.; Martinov, M. 3 - The Use of Electrostatic Potential Fields in QSAR and QSPR. In Molecular Electrostatic Potentials; Murray, J. S., Sen, K. B. T.-T. and C. C., Eds.; Elsevier, 1996; Vol. 3, pp 143-179. https://doi.org/10.1016/S1380-7323(96)80043-4.

53. Politzer, P.; Laurence, P. R.; Jayasuriya, K. Molecular Electrostatic Potentials: An Effective Tool for the Elucidation of Biochemical Phenomena. Environ. Health Perspect. 1985, 61, 191-202. https://doi.org/10.1289/ehp.8561191.

54. Politzer, P.; Murray, J. S. Electrostatic Potentials at the Nuclei of Atoms and Molecules. Theor. Chem. Acc. 2021, 140, 7. https://doi.org/10.1007/s00214-020-02701-0.

55. Politzer, P.; Murray, J. S. Molecular Electrostatic Potentials and Chemical Reactivity. In Reviews in 
Computational Chemistry. 1991, 273-312. https://doi.org/10.1002/9780470125793.ch7.

56. Fuster, F.; Sevin, A.; Silvi, B. Topological Analysis of the Electron Localization Function (ELF) Applied to the Electrophilic Aromatic Substitution. J. Phys. Chem. A 2000, 104, 852-858. https://doi.org/10.1021/jp992783k.

57. Koumpouras, K.; Larsson, J. A. Distinguishing between Chemical Bonding and Physical Binding Using Electron Localization Function (ELF). J. Phys. Condens. Matter 2020, 32, 315502. https://doi.org/10.1088/1361-648x/ab7fd8.

58. Gibbs, G. V; Cox, D. F.; Boisen Jr., M. B.; Downs, R. T.; Ross, N. L. The Electron Localization Function: A Tool for Locating Favorable Proton Docking Sites in the Silica Polymorphs. Phys. Chem. Miner. 2003, 30, 305-316. https://doi.org/10.1007/s00269-003-0318-2.

59. Politzer, P.; Murray, J. S.; Bulat, F. A. Average Local Ionization Energy: A Review. J. Mol. Model. 2010, 16, 1731-1742. https://doi.org/10.1007/s00894-010-0709-5.

60. Politzer, P.; Abu-Awwad, F.; Murray, J. S. Comparison of Density Functional and Hartree-Fock Average Local Ionization Energies on Molecular Surfaces. Int. J. Quantum Chem. 1998, 69, $607-613$. https://doi.org/10.1002/(SICI)1097-461X(1998)69:4<607::AID-QUA18>3.0.CO;2-W.

61. Hossain, M.; Thomas, R.; Mary, Y. S.; K.S.Resmi; Armaković, S.; Armaković, S. J.; Nanda, A. K.; Vijayakumar, G.; Alsenoy, C. Van. Understanding Reactivity of Two Newly Synthetized Imidazole Derivatives by Spectroscopic Characterization and Computational Study. J. Mol. Struct. 2018, 1158, 176196. https://doi.org/10.1016/j.molstruc.2018.01.029.

62. Armaković, S.; Armaković, S. J.; Vraneš, M.; Tot, A.; Gadžurić, S. Determination of Reactive Properties of 1-Butyl-3-Methylimidazolium Taurate Ionic Liquid Employing DFT Calculations. J. Mol. Liq. 2016, 222 , 796-803. https://doi.org/10.1016/J.MOLLIQ.2016.07.094.

63. Goerigk, L.; Grimme, S. Efficient and Accurate Double-Hybrid-Meta-GGA Density Functionals- Evaluation with the Extended GMTKN30 Database for General Main Group Thermochemistry, Kinetics, and Noncovalent Interactions. J. Chem. Theory Comput. 2011, 7, 291-309. https://doi.org/10.1021/ct100466k.

64. Grimme, S.; Hujo, W.; Kirchner, B. Performance of Dispersion-Corrected Density Functional Theory for the Interactions in Ionic Liquids. Phys. Chem. Chem. Phys. 2012, 14, 4875-4883. https://doi.org/10.1039/C2CP24096C.

65. Grimme, S. Density Functional Theory with London Dispersion Corrections. Wiley Interdiscip. Rev. Comput. Mol. Sci. 2011, 1, 211-228. https://doi.org/10.1002/wcms.30.

66. Grimme, S.; Ehrlich, S.; Goerigk, L. Effect of the Damping Function in Dispersion Corrected Density Functional Theory. J. Comput. Chem. 2011, 32, 1456-1465. https://doi.org/10.1002/jcc.21759.

67. Grimme, S. Semiempirical Hybrid Density Functional with Perturbative Second-Order Correlation. J. Chem. Phys. 2006, 124, 034108. https://doi.org/10.1063/1.2148954.

68. Kumar, A.; Manimekalai, M. S. S.; Balakrishna, A. M.; Jeyakanthan, J.; Grüber, G. Nucleotide Binding States of Subunit A of the A-ATP Synthase and the Implication of P-Loop Switch in Evolution. J. Mol. Biol. 2010, 396, 301-320. https://doi.org/10.1016/j.jmb.2009.11.046.

69. Al-Zaqri, N.; Pooventhiran, T.; Alsalme, A.; Rao, D. J.; Rao, S. S.; Sankar, A.; Thomas, R. First-Principle Studies of Istradefylline with Emphasis on the Stability, Reactivity, Interactions and WavefunctionDependent Properties. Polycycl. Aromat. Compd. https://doi.org/10.1080/10406638.2020.1857273

70. Almuqrin, A. H.; Al-Otaibi, J. S.; Mary, Y. S.; Thomas, R.; Kaya, S.; Işın, D. Ö. Spectral Analysis and Detailed Quantum Mechanical Investigation of Some Acetanilide Analogues and Their Self-Assemblies with Graphene and Fullerene. J. Mol. Model. 2020, 26, 254. https://doi.org/10.1007/s00894-020-04485-3.

71. Srikanth, K. E.; Veeraiah, A.; Pooventhiran, T.; Thomas, R.; Solomon, K. A.; Raju, C. J. S.; Latha, J. N. L. Detailed Molecular Structure (XRD), Conformational Search, Spectroscopic Characterization (IR, Raman, UV, Fluorescence), Quantum Mechanical Properties and Bioactivity Prediction of a Pyrrole Analogue. Heliyon 2020, 6, e04106. https://doi.org/10.1016/j.heliyon.2020.e04106

72. Al-Otaibi, J. S.; Almuqrin, A. H.; Mary, Y. S.; Thomas, R. Modeling the Conformational Preference, Spectroscopic Properties, UV Light Harvesting Efficiency, Biological Receptor Inhibitory Ability and Other Physico-Chemical Properties of Five Imidazole Derivatives Using Quantum Mechanical and Molecular Mechanics T. J. Mol. Liq. 2020, 310, 112871. https://doi.org/10.1016/j.molliq.2020.112871

73. John, A. M.; Jose, J.; Thomas, R.; Thomas, K. J.; Balakrishnan, S. P. Spectroscopic and TDDFT Investigation of Highly Selective Fluoride Sensors by Substituted Acyl Hydrazones. Spectrochim. Acta Part A Mol. Biomol. Spectrosc. 2020, 236, 118329. https://doi.org/10.1016/j.saa.2020.118329. 
74. Priya, Y. S.; Rao, K. R.; Chalapathi, P. V.; Veeraiah, A.; Srikanth, K. E.; Mary, Y. S.; Thomas, R. Intricate Spectroscopic Profiling, Light Harvesting Studies and Other Quantum Mechanical Properties of 3-Phenyl5-Isooxazolone Using Experimental and Computational Strategies. J. Mol. Struct. 2020, 1203, 127461. https://doi.org/10.1016/j.molstruc.2019.127461.

75. Alsalme, A.; Pooventhiran, T.; Al-Zaqri, N.; Rao, D. J.; Rao, S. S.; Thomas, R. Modelling the Structural and Reactivity Landscapes of Tucatinib with Special Reference to Its Wavefunction-Dependent Properties and Screening for Potential Antiviral Activity. J. Mol. Model. 2020, 26, 341. https://doi.org/10.1007/s00894020-04603-1.

76. Sheena Mary, Y.; Ertan-Bolelli, T.; Thomas, R.; Krishnan, A. R.; Bolelli, K.; Kasap, E. N.; Onkol, T.; Yildiz, I. Quantum Mechanical Studies of Three Aromatic Halogen-Substituted Bioactive Sulfonamidobenzoxazole Compounds with Potential Light Harvesting Properties. Polycycl. Aromat. Compd. 2019, In Press. https://doi.org/10.1080/10406638.2019.1689405.

77. Rao, D. J.; Mary, Y. S.; Mary, Y. S.; Resmi, K. S.; Thomas, R. Structure, Spectral Features, Bioactivity and Light Harvesting Properties of Methyl and Dimethyl Anthracene: Experimental and First Principle Studies. Polycycl. Aromat. Compd. 2019, 1-15. https://doi.org/10.1080/10406638.2019.1709083

78. Al-Otaibi, J. S.; Mary, Y. S.; Mary, Y. S.; Thomas, R. Quantum Mechanical and Photovoltaic Studies on the Cocrystals of Hydrochlorothiazide with Isonazid and Malonamide. J. Mol. Struct. 2019, 1197, 719-726. https://doi.org/10.1016/j.molstruc.2019.07.110.

79. Thadathil, D. A.; Varghese, S.; Akshaya, K. B.; Thomas, R.; Varghese, A. An Insight into Photophysical Investigation of (E)-2-Fluoro-N'-(1-(4-Nitrophenyl)Ethylidene)Benzohydrazide through Solvatochromism Approaches and Computational Studies. J. Fluoresc. 2019, 29, 1013-1027. https://doi.org/10.1007/s10895019-02415-y.

80. Matondo, A.; Thomas, R.; Tsalu, P. V.; Mukeba, C. T.; Mudogo, V. $\alpha$-Methylation and $\alpha$-Fluorination Electronic Effects on the Regioselectivity of Carbonyl Groups of Uracil by $\mathrm{H}$ and Triel Bonds in the Interaction of $\mathrm{U}, \mathrm{T}$ and 5FU with $\mathrm{HCl}$ and $\mathrm{TrH} 3(\mathrm{Tr}=\mathrm{B}, \mathrm{Al})$. J. Mol. Graph. Model. 2019, 88, $237-246$. https://doi.org/10.1016/j.jmgm.2019.02.006.

81. Thomas, R.; Mary, Y. S.; Resmi, K. S.; Narayana, B.; Sarojini, B. K.; Vijayakumar, G.; Van Alsenoy, C. Two Neoteric Pyrazole Compounds as Potential Anti-Cancer Agents: Synthesis, Electronic Structure, Physico-Chemical Properties and Docking Analysis. J. Mol. Struct. 2019, 1181, 455-466. https://doi.org/10.1016/j.molstruc.2019.01.003.

82. Sajini, T.; Thomas, R.; Mathew, B. Rational Design and Synthesis of Photo-Responsive Molecularly Imprinted Polymers for the Enantioselective Intake and Release of L-Phenylalanine Benzyl Ester on Multiwalled Carbon Nanotubes. Polymer 2014 2. https://doi.org/10.1016/j.polymer.2019.04.031.

83. Mary, Y. S.; Mary, Y. S.; Resmi, K. S.; Kumar, V. S.; Thomas, R.; Sureshkumar, B. Detailed Quantum Mechanical, Molecular Docking, QSAR Prediction, Photovoltaic Light Harvesting Efficiency Analysis of Benzil and Its Halogenated Analogues. Heliyon 2019, 5, e2825. https://doi.org/10.1016/j.heliyon.2019.e02825.

84. Mary, Y. S.; Mary, Y. S.; Resmi, K. S.; Thomas, R. DFT and Molecular Docking Investigations of Oxicam Derivatives. Heliyon 2019, 5, e02175. https://doi.org/10.1016/j.heliyon.2019.e02175. 


\section{Supplementary materials}

Table S1. Definition of local-symmetry coordinates and the values of corresponding scale factors used to correct the B3LYP/6-31G++ (d, p)force field calculations of N-N'-dimethylethyleneurea

\begin{tabular}{|c|c|c|c|}
\hline No.(i) & Symbol $^{\text {a }}$ & Definition $^{b}$ & Scale factors \\
\hline \multicolumn{4}{|c|}{ Stretching } \\
\hline 1 & $v$ C-C (Ring) & R1 & 0.999 \\
\hline $2-5$ & $v$ C-N (Ring) & R2, R3, R4, R5 & 0.993 \\
\hline $6-7$ & $v$ C-N sub & R6, R7 & 0.993 \\
\hline 8 & $v \mathrm{C}-\mathrm{O}$ & R8 & 0.451 \\
\hline $9-10$ & $v \mathrm{C}-\mathrm{H}$ ss & $(\mathrm{R} 9+\mathrm{R} 10) / \sqrt{2},(\mathrm{R} 11+\mathrm{R} 12) / \sqrt{2}$ & 0.905 \\
\hline $11-12$ & $v \mathrm{C}-\mathrm{H}$ ass & $(\mathrm{R} 9-\mathrm{R} 10) / \sqrt{2},(\mathrm{R} 11-\mathrm{R} 12) / \sqrt{2}$ & 0.994 \\
\hline $13-14$ & vCH3ss & (R13+R14+R15), (R16+R17+R18) & 0.660 \\
\hline $15-16$ & $v$ CH3ips & $(2 \mathrm{R} 13-\mathrm{R} 14-\mathrm{R} 15) / \sqrt{6},(2 \mathrm{R} 16-\mathrm{R} 17-\mathrm{R} 18) / \sqrt{6}$ & 0.899 \\
\hline $17-18$ & $v \mathrm{CH} 3$ ops & $(\mathrm{R} 14-\mathrm{R} 15) / \sqrt{2},(\mathrm{R} 17-\mathrm{R} 18) / \sqrt{2}$ & 0.999 \\
\hline \multicolumn{4}{|c|}{ In-Plane bending } \\
\hline 19 & $\beta$ Rasy & $\gamma 19+\mathrm{a}(\gamma 20+\gamma 23)-\mathrm{b}(\gamma 21+\gamma 22)$ & 0.998 \\
\hline 20 & $\beta$ Rsym & $(a-b)(\gamma 20-\gamma 23)+(a+b)(\gamma 21-\gamma 22)$ & 0.997 \\
\hline $21-22$ & $\beta \mathrm{CH}_{2} \mathrm{Sc}$ & $(\gamma 24+\gamma 28+\gamma 25+\gamma 29) / 2,(\gamma 26+\gamma 30+\gamma 27+\gamma 31) / 2$ & 0.865 \\
\hline $23-24$ & $\beta_{\mathrm{CH}}$ ro & $(\gamma 24+\gamma 28-\gamma 25-\gamma 29) / 2,(\gamma 26+\gamma 30-\gamma 27-\gamma 31) / 2$ & 0.875 \\
\hline $25-26$ & $\beta \mathrm{CH}_{2}$ wa & $(\gamma 24-\gamma 28+\gamma 25-\gamma 29) / 2,(\gamma 26-\gamma 30+\gamma 27-\gamma 31) / 2$ & 0.865 \\
\hline $27-28$ & $\beta \mathrm{CH}_{2} \mathrm{tw}$ & $(\gamma 24-\gamma 28-\gamma 25+\gamma 29) / 2,(\gamma 26-\gamma 30-\gamma 27+\gamma 31) / 2$ & 0.999 \\
\hline $29-30$ & $\beta(\mathrm{N}-\mathrm{C})$ & $(\gamma 32-\gamma 33) / \sqrt{ } 2,(\gamma 34-\gamma 35) / \sqrt{ } 2$ & 0.907 \\
\hline 31 & $\beta(\mathrm{N}-\mathrm{C}-\mathrm{O})$ & $(\gamma 36-\gamma 37) / \sqrt{ } 2$ & 0.957 \\
\hline $32-33$ & $\mathrm{\beta CH}_{3} \mathrm{sb}$ & $\begin{array}{l}(-\gamma 38-\gamma 39-\gamma 40+\gamma 44+\gamma 45+\gamma 46) / \sqrt{ } 6 \\
(-\gamma 41-\gamma 42-\gamma 43+\gamma 47+\gamma 48+\gamma 49) / \sqrt{ } 6\end{array}$ & 0.960 \\
\hline $34-35$ & $\beta \mathrm{CH}_{3} \mathrm{ipb}$ & $(-\gamma 44-\gamma 45-2 \gamma 46) / \sqrt{ } 6,(-\gamma 47-\gamma 48-2 \gamma 49) / \sqrt{ } 6$ & 0.999 \\
\hline $36-37$ & $\beta \mathrm{CH}_{3} \mathrm{opr}$ & $(\gamma 44+\gamma 45) / \sqrt{6},(\gamma 46+\gamma 47) / \sqrt{6}$ & 0.625 \\
\hline $38-39$ & $\beta \mathrm{CH}_{3}$ ipr & $(2 \gamma 38-\gamma 39-\gamma 40) / \sqrt{ } 6,(2 \gamma 41-\gamma 42-\gamma 43) / \sqrt{ } 6$ & 0.830 \\
\hline $40-41$ & $\beta \mathrm{CH}_{3} \mathrm{opr}$ & $(\gamma 39-\gamma 40) / \sqrt{ } 6,(\gamma 42-\gamma 43) / \sqrt{ } 6$ & 0.999 \\
\hline \multicolumn{4}{|c|}{ Out of plane bending } \\
\hline 42 & $\omega(\mathrm{C}-\mathrm{O})$ & $\rho 50$ & 0.995 \\
\hline $43-44$ & $\omega(\mathrm{C}-\mathrm{N})$ & $\rho 51, \rho 52$ & 0.995 \\
\hline \multicolumn{4}{|c|}{ Torsion } \\
\hline 45 & $\tau$ Rasy & $\mathrm{b}(\tau 53+\tau 57)+\mathrm{a}(\tau 54+\tau 56)+\tau 55$ & 0.987 \\
\hline 46 & $\tau$ Rsym & $(a-b)(\tau 56-\tau 54)+(1-a)(\tau 57-\tau 53)$ & 0.999 \\
\hline $47-48$ & $\tau \mathrm{N}-\mathrm{CH} 3$ & $\tau 60, \tau 61$ & 0.850 \\
\hline
\end{tabular}

Where $a=\cos 1440, b=\cos 720$.

Abbreviations: $v$, stretching; $\beta$, in plane bending; $\omega$, out of plane bending; $\tau$, torsion, ss, symmetrical stretching, ass, asymmetrical stretching, sc, scissoring, wa, wagging, tw, twisting, ro, rocking, tri, trigonal deformation, sym, symmetrical deformation, asy, asymmetric deformation, sub, substitution.

a These symbols are used for description of the normal modes by PED

b The internal coordinates used here are defined in table given in supplementary material 1 


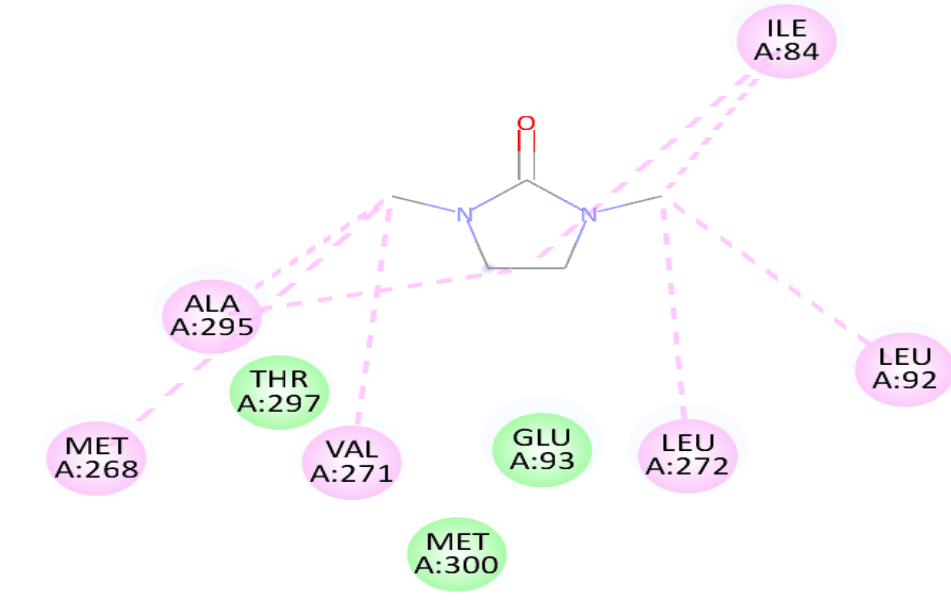

Interactions

Figure S1. Hydrophobic interactions between N-N'-dimethylethylene urea and protein residues.

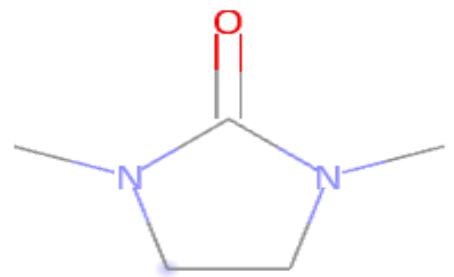

\section{THR}

A:297

\section{GLU}

A:93

\section{Interactions}

van der Waals

Figure S2. Hydrophilic and acid interactions between N-N'-dimethylethylene urea and protein residues.

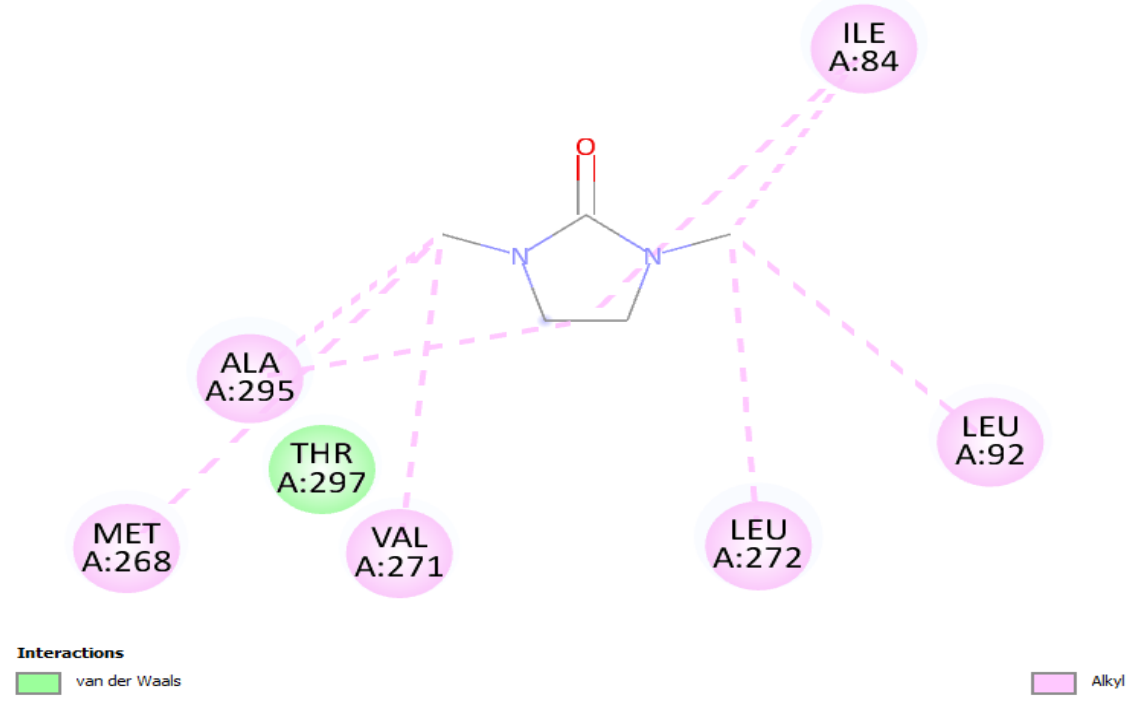

Figure S3. Neutral group interactions between N-N'-dimethylethylene urea and protein residues. 